\title{
Novel imprints in mouse blastocysts are predominantly DNA methylation independent
}

\author{
${\text { Laura Santini }{ }^{1 *} \text {, Florian Halbritter }}^{2,3^{*}}$, Fabian Titz-Teixeira ${ }^{4}$, Toru Suzuki ${ }^{5}$, Maki Asami ${ }^{5}$, Julia \\ Ramesmayer ${ }^{1}$, Xiaoyan Ma ${ }^{6}$, Andreas Lackner ${ }^{1}$, Nick Warr ${ }^{7}$, Florian Pauler $^{8}$, Simon \\ Hippenmeyer ${ }^{8}$, Ernest Laue ${ }^{6}$, Matthias Farlik ${ }^{3}$, Christoph Bock $^{3,9}$, Andreas Beyer ${ }^{4}$, Anthony \\ C. F. Perry ${ }^{5 \#}$ and Martin Leeb ${ }^{1 \#}$
}

${ }^{1}$ Max Perutz Laboratories Vienna, University of Vienna, Vienna Biocenter, Dr. Bohr-Gasse 9, 1030 Vienna, Austria.

${ }^{2}$ St. Anna Children's Cancer Research Institute (CCRI), Zimmermannplatz 10, 1090 Vienna, Austria.

${ }^{3}$ CeMM Research Center for Molecular Medicine of the Austrian Academy of Sciences, Lazarettgasse 14, 1090

Vienna, Austria.

${ }^{4}$ CECAD, University of Cologne, Joseph-Stelzmann-Straße 26, 50931 Cologne, Germany.

${ }^{5}$ Laboratory of Mammalian Molecular Embryology, Department of Biology and Biochemistry, University of Bath, BA2 7AY, England.

${ }^{6}$ Department of Biochemistry, University of Cambridge, 80 Tennis Court Road, Cambridge CB2 1GA, United Kingdom.

${ }^{7}$ Mammalian Genetics Unit, MRC Harwell Institute, Oxfordshire, OX11 ORD, England.

${ }^{8}$ Institute for Science and Technology Austria, Am Campus 1, 3400 Klosterneuburg, Austria

${ }^{9}$ Department of Laboratory Medicine, Medical University of Vienna, Vienna, Austria

*equal contribution

\#Corresponding authors; equal contribution

Key words: haploid ES cells, parent-of-origin, monoallelic gene expression; DNA methylation; imprinting; mouse; preimplantation development; reciprocal cross; androgenesis; parthenogenesis 


\section{ABSTRACT}

In mammals, chromatin marks at imprinted genes are asymmetrically inherited to control parentally-biased gene expression. This control is thought predominantly to involve parentspecific differentially methylated regions (DMR) in genomic DNA. However, neither parent-

5 of-origin-specific transcription nor DMRs have been comprehensively mapped. We here address this by integrating transcriptomic and epigenomic approaches in mouse preimplantation embryos (blastocysts). Transcriptome-analysis identified 71 genes expressed with previously unknown parent-of-origin-specific expression in blastocysts (nBiX: novel blastocyst-imprinted expression). Uniparental expression of nBiX genes disappeared soon after implantation. Micro-whole-genome bisulfite sequencing ( $\mu$ WGBS) of individual uniparental blastocysts detected 859 DMRs. Only $18 \%$ of nBiXs were associated with a DMR, whereas $60 \%$ were associated with parentally-biased H3K27me3. This suggests a major role for Polycomb-mediated imprinting in blastocysts. Five nBiX-clusters contained at least one known imprinted gene, and five novel clusters contained exclusively nBiX-genes. These data suggest a complex program of stage-specific imprinting involving different tiers of regulation. 


\section{INTRODUCTION}

Most mammalian genes are active on both parental alleles, but some are expressed from only one, determined by the parent-of-origin, and are said to be imprinted. Balanced expression of imprinted genes is critical ${ }^{1,2}$ as development stops around the time of implantation in uniparental diploid embryos ${ }^{1,3,4}$. Multiple databases of imprinted genes exist that collectively list 388 genes with parent-of-origin expression bias in mice ${ }^{5-7}$ 1,8 (http://www.geneimprint.com/). Imprinting is associated with chromatin marks that include allele-specific DNA methylation and/or H3K27me ${ }^{9}$. DNA methylation-based imprints are associated with differentially methylated regions (DMRs). Many DMRs are established during gametogenesis in a Dnmt3l-dependent manner to produce germline DMRs (GLDMRs) ${ }^{10}$. GL-DMRs are key constituents of each of the 24 known imprinting control regions (ICRs) in the mouse ${ }^{6,11,12}$.

30 Although uniparental embryos fail in early development, they form blastocysts from which pluripotent embryonic stem cells (ESCs) can be established. Haploid parthenogenetic (ph) and androgenetic (ah) embryos have been utilised for the derivation of haploid ESCs whose nuclei can be combined with complementary gametes to produce living mice, albeit inefficiently, in 'semi-cloning' ${ }^{13-16}$. The extent to which poor development in semi-cloning reflects imprinting instability is unclear and the DNA methylomes of mouse uniparental embryos have not been comprehensively evaluated. However, it is known that haploid ESCs lose canonical imprints over extended culture periods, which has been leveraged to generate bi-maternal mice ${ }^{17}$. 
40 In addition to genomic DNA methylation-based imprinting, a subset of genes with paternal expression bias in mouse preimplantation embryos is maternally enriched for $\mathrm{H} 3 \mathrm{~K} 27 \mathrm{me} 3$, without apparent direct dependence on DNA methylation. Most or all of this H3K27me3based imprinting is lost in extra-embryonic cell lineages and post-implantation ${ }^{9,18}$. However, the extent of imprinting control by both types of epigenetic mechanisms in mouse preimplantation development is unknown. Imprinting defects can have severe developmental consequences that can manifest themselves at, or shortly after implantation ${ }^{19}$. It is therefore likely that the imprinting landscape in blastocysts is a critical determinant of normal development, such that blastocyst imprinting dysregulation has serious detrimental developmental consequences ${ }^{20}$. We therefore sought to determine parent-oforigin-specific expression in biparental embryos and parent-of-origin-specific DNA methylation in uniparental blastocysts to delineate the imprinting landscape in mouse preimplantation embryos. 


\section{RESULTS}

\section{Assessing parent-of-origin-specific gene expression in F1-hybrid mouse blastocysts}

To delineate parent-of-origin expression bias in mouse blastocysts, we performed allelespecific transcriptome analyses (RNA-seq) of embryonic day 3.5 (E3.5) embryos obtained without in vitro culture from reciprocal Mus musculus domesticus C57BL/6 (B6) x Mus musculus castaneus (cast) natural mating (Fig. 1a). After exclusion of transcripts encoded by the X-chromosome, 10,743 robustly expressed transcripts were identified that contained informative single nucleotide polymorphisms (SNPs) $(\geq 12$ reads in at least four out of eight samples). The list included 134 of the combined catalogue of 388 genes previously reported to be imprinted ${ }^{1,8}$ and in repositories (Mousebook, Otago, Geneimprint, Wamidex) (referred to here as 'published imprinted genes'). We further categorized the group of published imprinted genes into those listed in at least one repository (67 'repository imprints') or in three or more repositories (30 'high confidence repository imprints').

Four hundred and nine (409) genes showed significant cast-specific, and 1001 significant B6specific strain-dependent expression bias (adj. $p \leq 0.05$, and further filtered for consistency across all samples). A further 141 genes exhibited parent-of-origin-specific expression in blastocysts (Fig. 1b; adj. $p \leq 0.1$ and further filtered for consistency across all samples). To increase stringency, we imposed a requirement for consistent allelic expression ratio of at least 70:30 between parental alleles in a minimum of $60 \%$ of embryos for forward and reverse crosses. We refer to the first group of 141 transcripts as 'blastocyst-skewed expressed' genes (BsX), and those fulfilling the 70:30 criterion as 'blastocyst-imprinted expressed' genes (BiX; 105 transcripts). 

for BsX; Fig. 1c and Extended Data Fig. 1a). Paternal expression of S/c38a4, Peg3, Otx2 and Bbx was confirmed in independent reciprocal crosses by RT-PCR followed by Sanger sequencing (Fig. 1d; Extended Data Fig. 1c). A large proportion of the published imprinted genes (100 of 134, including Igf2, H13 and Commd1) were absent from the BiX dataset (99 for BsX). We therefore re-evaluated whether these previously reported imprinted genes were indeed expressed equivalently from both alleles, or whether lack of statistical power may have prevented detection. To this end, we performed a statistical test for equivalent expression from paternal and maternal alleles. Across all analysed genes this identified statistically significant biallelic expression for 5376 genes (adj. $p \leq 0.1, \mathrm{HO}$ : absolute log2FC $\geq$ 1), including 24 out of the 134 (18\%) published imprinted genes with SNP-containing reads (Fig. 1c). RT-PCR Sanger sequencing of independent reciprocal cross E3.5 blastocysts revealed that Commd1 indeed exhibited mixed expression states (with sample-dependent allele-specific or biallelic expression) and Pon2 had clear strain-biased expression in blastocysts (Extended Data Fig. 1b). Hence, statistically significant parent-of-origin-specified gene expression was detected in blastocysts for only a quarter of all published imprinted genes. Of note, $18 \%$ of published imprinted genes were biallelically expressed in blastocysts with statistical significance, indicating a strong impact of tissue and cell type in defining imprinting patterns during development. 


\section{Identification of novel imprinted genes}

Groups of 71 (56 paternal, 15 maternal) and 106 (76 paternal, 30 maternal) genes that did not include published imprinted genes respectively constitute sets of novel $\mathrm{BiX}$ (nBiX) or novel BsX (nBsX) genes (Fig. 1c; Extended Data Fig. 1c). RT-PCR Sanger sequencing of independent crosses confirmed uniparental expression of the paternally-expressed $\mathrm{nBiX}$ genes Pmaip1, Smyd2, Cblb, Myo1a and of maternally-expressed nBiX Emc2 in E3.5 blastocysts (Fig. 1e). Parent-of-origin-biased expression of tested nBiXs was lost by E6.5 (Fig. 1g), similar to the recently reported H3K27me3-dependent imprinted genes Otx2 and Bbx ${ }^{9}$, but in contrast to high confidence repository imprinted genes, Slc38a4 and Peg3, which we found maintained uniparental expression at E6.5 (Fig. 1f; Extended Data Fig. 1e). We further confirmed parent-of-origin-specific expression of the BsX genes Wrap53, Tmem144 and Sri (Extended Data Figure 1d and f) in independent crosses, suggesting consistent parental allele expression bias across multiple samples and experiments. Allele-specific expression analysis of available single-cell sequencing data confirmed parental expression bias of BiX and BsX (both novel and confirmed published imprinted genes), despite sparsity of signal (Extended Data Fig. 1g) ${ }^{18}$. In accordance with our data, unconfirmed published imprinted genes did not exhibit clear allelic bias in the single-cell data. Our data accordingly identify sets of nBiX and nBsX genes with high confidence, parent-of-origin-specific blastocyst expression bias.

115 The $\mathrm{nBiX}$ set was enriched for genes up-regulated in cells lacking the PRC2 (Polycomb Repressive Complex 2) component Eed (Fig. 1h). Eed regulates H3K27me3 ${ }^{21}$, a DNA methylation independent imprinting mark ${ }^{9,22,23}$. Genes upregulated in ESCs upon loss of the pluripotency factors Oct4 (Pou5f1) or Nanog were also enriched among nBiXs and confirmed 
bioRxiv preprint doi: https://doi org/10.1101/2020.11.03.366948; this version posted November 5,2020 . The copyright holder for this preprint (which was not certified by peer review) is the author/funder, who has granted bioRxiv a license to display the preprint in perpetuity. It is made available under aCC-BY-NC-ND 4.0 International license.

published imprints, revealing an intersection between blastocyst imprinting and

pluripotency circuitries. Both published confirmed imprinted and $\mathrm{nBiX}$ genes exhibited more dynamic transcriptional regulation during the first 24 hours of ESC differentiation 24 compared to biallelically-expressed genes (Extended Data Fig. 1h). This indicates that genes showing parent-of-origin-specific gene expression in blastocysts are involved in, or responsive to early embryonic cell fate specification.

\section{Capturing parent-of-origin-specific DNA methylation in uniparental mouse blastocysts}

Imprinted gene expression has conventionally been associated with parent-of-origin-biased genomic DNA methylation. To assess whether parentally-specified nBiX expression could also be explained in this way, we measured genome-wide DNA methylation in individual haploid uniparental parthenogenetic haploid (ph) and androgenetic haploid (ah) E3.5 blastocysts by micro-whole-genome bisulfite sequencing ( $\mu$ WGBS) $15,25,26$. We selected haploid embryos in an effort to reduce noise that might otherwise have been contributed by different alleles in diploid uniparental embryos. Moreover, uniparental embryos allow unambiguous mapping of $\mu$ WGBS reads to chromosomes with known parental provenance.

Uniparental embryos efficiently formed expanded blastocysts and contained cells expressing readily-detectable Oct4 and Sox2 (Extended Data Fig. 2a and b). For comparison, we also derived ahESC and phESC lines and included three androgenetic, four parthenogenetic and five biparental ESC lines and somatic tissue (kidney) in the $\mu$ WGBS analysis (Fig. 2a). 
DNA methylation levels could be quantified at 11 to 16.5 million CpGs per sample. Uniparental blastocysts exhibited $\sim 25 \%$ global CpG methylation, independently of parental provenance, compared with $\sim 70 \%$ CpG methylation in the kidney (Fig. 2b) and in line with $20 \%$ genomic methylation previously reported for the blastocyst inner cell mass ${ }^{27}$. These data show that blastocyst global DNA methylation levels are independent of the parent-oforigin. Investigation of DNA methylation levels across published ICRs unambiguously confirmed parent-of-origin-specific methylation differences at most (22 out of 24) known GL-DMRs in haploid uniparental embryos (Fig. 2c). The two we did not detect across all samples were Snrpn, whose DMR lacked coverage in two samples, and Liz1/Zdbf2, whose DMR showed no evidence of DNA methylation in one of the intracytoplasmic sperm injection (ICSI)-derived replicates, confounding unambiguous identification. The uniparental embryo data thus efficiently detected GL-DMRs with a precision that may surpass that obtained for biparental F1 hybrid blastocysts or long read sequencing ${ }^{27,28}$ (Extended Data Figure 2c).

Of six DMRs reportedly acquired in somatic tissues ${ }^{6}$, we found that none were uniparentally methylated in blastocysts (Extended Data Figure 2d). The implication of this is that these loci carry marks at the blastocyst stage that are not directly dependent on DNA-methylation, and that do not become manifest as DNA methylation until after implantation. This is reminiscent of germ-line-independent somatic DMR acquisition on an $H 19$ transgene ${ }^{29}$. The mechanism of this implicit DNA-methylation-independent preimplantation imprinting program and the means by which it is converted into DNA methylation, are unknown ${ }^{29,30}$. 


\section{DMR erosion in uniparental haploid ESCs}

Four out of five biparental ESC lines maintained GL-DMR methylation levels similar to those in ICSI embryos when cultured in 2i/LIF medium; one female line (ESf1) exhibited erosion specifically of maternal DMRs (Fig. 2c), but imprint status was generally independent of sex and passage number. All biparental lines had strongly reduced DNA methylation of the Gnas ICR. The DNA methylation signal was reduced in some, but not all ESC lines on S/c38a4 and Liz1/Zdbf2 DMRs, suggesting differential stability of DMRs in ESC culture. In contrast, similarly-cultured haploid ESC lines typically underwent widespread DMR erosion regardless of their parental provenance. Androgenetic ESCs underwent near-complete erosion of all methylation over paternally-deposited H19/Igf2 and DIk1 GL-DMRs (Fig. 2c). Methylation of the Rasgrf1 GL-DMR was at lower levels than in biparental embryos, indicating ongoing loss of DNA methylation. Parthenogenetic haploid ESCs exhibited greater variability in GL-DMR methylation loss than their androgenetic (ahESC) counterparts. In two phESC lines, most maternal DMRs were maintained at levels similar to those of biparental ESCs, but even then, DMR signals were reduced compared to ph blastocysts, indicating that phESCs can maintain DMRs in culture, but undergo varying levels of DMR loss. Consistent with DMR dysregulation, ahESCs and phESCs lacked parent-of-origin biased expression of tested known imprinted genes (Meg3, Peg3, Slc38a4 and Jade1), despite possessing unperturbed naïve pluripotency and the potential to initiate differentiation (Extended Data Fig.2e and f). Relative DMR stability in parthenogenotes compared to androgenotes contrasts with previous reports ${ }^{17}$. These findings further support the idea that imprint erosion does not strictly reflect parental origin. However, imprint erosion in ahESCs would explain why the vast majority failed to support 'semi-cloning'; embryos produced by injecting ahESC nuclei into mature oocytes 
would lack a balanced set of imprinted genes, resulting in developmental attenuation prior to, or around the time of implantation, as we observed ${ }^{3,4}$. In summary, uniparental ESCs exhibited variable loss of DMRs, even though the DMRs were robustly detectable in uniparental blastocysts.

\section{Identification of novel blastocyst DMRs}

Corroboration of known GL-DMRs allowed us to ask whether our data also revealed novel DMRs in blastocysts. Comparison of genome-wide DNA methylomes from ah and ph blastocysts with those of control blastocysts produced by intracytoplasmic sperm injection (ICSI) identified 859 DMRs (dmrseq, adj. $p \leq 0.1)^{31}$. Of these, $778(91 \%)$ were maternal (that is, the marks were enriched in parthenogenotes) and 81 (9\%) paternal (enriched in androgenotes) (Fig. 3a). The DMRs were associated with 3,664 (7,031) and 392 (779) annotated genes within 100 (or 250 ) kb windows, respectively; $250 \mathrm{~kb}$ is well within the $\sim 300$ $\mathrm{kb}$ size of the $\operatorname{lgf} 2 r$ cluster ${ }^{2,32}$. Unbiased embryo analysis recovered 23 of the 24 known GLDMRs and in most cases coordinates of novel DMRs were superimposable upon those of published DMRs (Fig. 3b). For Snrpn, we detected a new DMR 1kb from the annotated Snrpn GL-DMR potentially extending the Snrpn DMR (Extended Data Fig.3a). Only the Liz1/Zdbf2 GL-DMR was not confidently identified in our analysis, because it lacked a DNA methylation signal in one of the ICSI samples (Fig. 2c). As for known ICRs, patterns of blastocyst-derived DMRs identified here were not maintained in haploid ESCs (Extended Data Fig.3b). 
We next analysed available oocyte and sperm DNA methylome data ${ }^{27}$ to determine the developmental origins of the 859 DMRs. Of our 778 maternal DMRs, 410 (52\%) exhibited oocyte-specific or oocyte-biased DNA methylation (clusters C1 and C4, respectively) (Fig. 3c) and 62 of the 81 (76\%) paternal DMRs were methylated in sperm genomes (cluster C5). Notably, 349 blastocyst-DMRs (41\% of the total) were established during preimplantation development by loss of DNA methylation on one allele, typically the paternal one (cluster C2) ${ }^{1}$. Thirty-seven blastocyst DMRs exhibited little or no DNA methylation in oocytes or sperm (cluster C3). These data collectively suggest that most differential DNA methylation is encoded within gamete genomes, even though DMRs may not become manifest until later in development. detected an overlap with gene promoters and CpG islands of $\sim 25 \%$. We asked which chromatin regulators might interact with the identified DMRs using two complementary bioinformatics approaches. First, we tested for overlaps between DMRs and binding regions of transcription factors and chromatin modifiers by mining 791 published ChIP-Seq datasets 33-35. This identified enrichments of the H3K9-specific histone-lysine methyltransferase Setdb1 and the zinc finger protein Zfp445, after subtracting overlaps generally detected in promoters (Fig. 3e). Setdb1 establishes H3K9me3, an imprint-associated chromatin mark ${ }^{36}$ and Zfp445 is a primary regulator of genomic imprinting ${ }^{37}$. Secondly, we searched the DMRs for matches to transcription factor DNA-binding motifs ${ }^{38}$. This detected an enrichment for Zfp57, E2f5, and Nrf1 cognate sequences (Fig. 3f), which were also enriched in known GLDMRs. Zfp57 synergistically contributes to imprint maintenance with Zpf445 ${ }^{30,37}$ and Nrf1 
bioRxiv preprint doi: https://doi.org/10.1101/2020.11.03 366948; this version posted November 5, 2020. The copyright holder for this preprint (which was not certified by peer review) is the author/funder, who has granted bioRxiv a license to display the preprint in perpetuity. It is made available under aCC-BY-NC-ND 4.0 International license.

Associating DMRs with parent-of-origin biased expression

Integrating parent-of-origin biased blastocyst transcriptome and DNA methylome data has the potential to reveal relationships between gene expression and DNA methylation. We found that the vast majority of both $\mathrm{nBiX}$ and $\mathrm{nBsX}$ genes exhibited paternal expression with maternal $5 \mathrm{mC}$ at the closest DMR, similar to published imprinted genes (Fig. 4a). However, whereas substantial numbers of both published imprinted $(62 / 134 ; 46 \%)$ and confirmed published imprinted $(12 / 34 ; 35 \%)$ genes resided close to a DMR $(<250 \mathrm{~kb}$ between DMR and gene), nBiX and nBsX did not show such an association (8/71 [11\%] and 15/106 [14\%], respectively) (Fig. 4b; Extended Data Fig. 4a and b). Moreover, even in published and confirmed published imprint gene sets, most genes (72/134 [54\%] and 22/34 [65\%], respectively) were not located near to a DMR, suggesting that proximal DMRs are not a defining feature of imprinted genes in blastocysts.

Only eight nBiX genes were within 250 kb of a DMR (Fig. 4b; Extended Data Fig. 4a). The large distance of most $\mathrm{nBiX}$ genes to their nearest DMR (relative to that of known imprinted genes) may be explained by long-range tertiary chromatin interactions between DMRs and nBiX loci. We addressed this possibility by utilizing HiC data from mouse ESCs 40 and investigated the concomitant presence of $\mathrm{nBiX}$ or $\mathrm{nBsX}$ with DMRs in the same topologically associated domain, TAD (Extended Data Fig. 4c). Even after considering DMR-gene pairs 
Recent research suggests that parent-of-origin-specific H3K27me3 functions in specifying imprinted gene expression in preimplantation development ${ }^{9}$. We therefore interrogated available datasets to map $\mathrm{H} 3 \mathrm{~K} 27 \mathrm{me} 3$ to the transcription start site (TSS) of parent-of-origin specific genes ${ }^{41}$. We identified parent-of-origin-specific H3K27me3 at the TSS of 741 out of all 10743 (7\%) genes with expression evidence in our datasets, and 217 out of $5376(4 \%)$ genes equivalently-expressed from both alleles, defining the genomic background. Fortyseven out of 134 (35\%) published imprinted genes showed an enrichment of parent-oforigin-specific $\mathrm{H} 3 \mathrm{~K} 27$ me3 on respective TSSs, which is less than the overlap with proximal DMRs (46\%) (Extended Data Fig.4d). This indicates that published imprinted genes are more closely associated with DMRs than with parent-of-origin-specific H3K27me3. However, 22 out of $34(65 \%)$ of the group of confirmed published imprinted genes exhibited parent-oforigin-specific TSS-associated $\mathrm{H} 3 \mathrm{~K} 27 \mathrm{me} 3$, suggesting that $\mathrm{H} 3 \mathrm{~K} 27 \mathrm{me} 3$ assists in regulating parent-of-origin-specific expression of known imprinted genes at the blastocyst stage. Both $\mathrm{nBiX}$ and $\mathrm{nBsX}$ exhibited only low levels of association to DMRs, but parent-of-origin-specific H3K27me3 peaks at promoters on par with those observed for confirmed published imprinted genes ( $54 \%$ and $45 \%$ for $\mathrm{nBiX}$ and $\mathrm{nBsX}$, respectively). This suggests that there is a senior role for Polycomb, and a junior one for DNA methylation, in regulating (n)BiX gene expression. Interestingly, we found that 5 out of 34 confirmed published imprinted genes (15\%), and 27 out of $71 \mathrm{nBiX}$ genes (38\%) were neither associated with parent-of-originspecific H3K27me3 nor with a proximal DMR. 


\section{H3K27me3 and DNA methylation}

Association with an epigenetic mark does not necessarily signify causality for mediating imprinted expression. To address whether the relationship was causal, we took advantage of available datasets mapping allele-specific expression of mouse morulae carrying a maternal deletion of either Dnmt3I (mDnmt3l matKO) or Eed (mEed matKO) ${ }^{42,43}$. We reasoned that genes showing allelically skewed expression in control embryos, which is lost or reduced upon maternal Dnmt3I (mDnmt3/) or Eed (mEed) depletion, would be regulated by DNA methylation or H3K27me3, respectively. Accordingly, we compared allele-specific expression in our datasets with the response of allelic skewing upon mDnmt3/ or mEed depletion in morula datasets (Fig. 5a-c). Whereas confirmed published imprinted genes showed only limited response to loss of $m D n m t 3 l$, there was a strong reduction of parentof-origin skewing in mEed KO morulae (Fig. 5a). For published imprinted genes that did not show parent-of-origin-specific expression in our datasets, there was no response to loss of either mDnmt3l or mEed (Fig. 4b). However, nBiX genes exhibited behaviours similar to those of confirmed published imprinted genes (Fig. 5c). We then mapped physical associations with DMRs (within $250 \mathrm{~kb}$ or in the same TAD) and parent-of-origin-specific H3K27me3 onto the KO expression data (Fig. 5a-c). This revealed an enrichment for parentof-origin-specific H3K27me3-decorated TSSs among genes responsive to loss of $m E e d$ among the groups of published confirmed imprinted and nBiX genes, but not for unconfirmed published imprinted genes. Together, these findings suggest a major role for H3K27me 3 in establishing and/or maintaining parent-of-origin specific expression in pre-implantation development. 
bioRxiv preprint doi: https://doi.org/10.1101/202011.03 366948; this version posted November 5, 2020. The copyright holder for this preprint (which was not certified by peer review) is the author/funder, who has granted bioRxiv a license to display the preprint in perpetuity. It is made available under aCC-BY-NC-ND 4.0 International license.

To identify those imprinted genes that show dependence on mEed or mDnmt3l, we considered that for dependent genes, parentally biased expression in wild-type (wt) morulae would be lost in mutant morulae (Extended Data Figure 5a, b). This analysis showed that imprinting was dependent on either mEed or $m D n m t 3 /$ for $60 \%$ of published confirmed imprinted genes (Fig. 5d; Extended Data Fig. 5b). Expression of $40 \%$ of nBiX and nBsX genes were dependent on maternal H3K27me3 or maternal DMRs. However, expression of some $50 \%$ of novel imprinted genes were apparently H3K27me3- and DMR-independent. blastocysts is not necessarily predicted to result in complete loss of allele-specific expression in $m E e d$ or $m D n m t 3 /$ mutant morulae, but may merely cause a reduction in allelic bias. This might, for example, be the case for genes that are coregulated by multiple chromatinregulatory mechanisms. We therefore asked whether expression of genes that fell below our strict cut-off exhibited loss of either known imprint-defining epigenetic mark. We defined genes as 'sensitive' if they exhibited allelic skewing in wt morulae and reduced allelic bias upon loss of mEed or mDnmt3l in morulae, even if some parental bias could still be detected. Eleven out of $19 \mathrm{nBiX}$ genes and 16 out of $31 \mathrm{nBsX}$ genes not showing dependence were sensitive to loss of either Dnmt3I or Eed (Fig. 5e; Extended Data Fig. 5c). The majority of strictly Eed/Dnmt3I-dependent, and -sensitive nBiX genes were marked by DMRs or allelespecific H3K27me3 (Fig. 5f). Only for four nBiX and six nBsX genes we could detect neither Eed/Dnmt3l dependence or sensitivity, nor the physical presence of known imprintassociated chromatin modifications. In summary, this shows that most novel blastocyst imprinted genes are regulated by parent-of-origin specific DNA methylation or H3K27me3. 
chromatin, plays a major role in establishing and/or maintaining imprinted expression of known and novel imprinted genes in the blastocyst.

\section{Identification of imprinted gene clusters in blastocysts}

Imprinted genes are known to reside in genomic clusters regulated by cis-acting imprinting control regions (ICRs) ${ }^{44-46}$. We therefore searched for clusters containing at least two published or novel (nBiX or nBsX) imprinted genes within $250 \mathrm{~kb}$, yielding 32 potential ICR clusters (Fig. 6a). Twelve clusters contained at least one published imprinted gene that exhibited uniparental expression in blastocysts (Fig. 6a, clusters \#1-12). Eight of these also contained a DMR within at least one of its associated genes or less than $10 \mathrm{~kb}$ away. One additional cluster encompassing the SIc38a1 gene contained a DMR within the same TAD. Strikingly, ten clusters of published imprinted genes (including the lgf2 cluster) lacked significant expression bias in blastocysts, despite exhibiting a DMR within the gene body in nine of these ten cases (Fig. 6a, clusters \#13-22). This suggests that in some cases, differential DNA methylation and parent-of-origin-specific expression is unlinked. A subset of six published imprinted genes in these clusters (including Commd1 and Grb10) contained both a DMR and parental-allele-specific H3K27me3 on their TSSs, but apparently neither of these epigenetic marks elicited allele specific gene expression. Our analyses extended five known imprinting clusters by identifying novel imprinted genes close to published examples (Fig. 6a, cluster \#23-27). Although these clusters were devoid of proximal DMRs, they were all associated with parent-of-origin-specific H3K27me3. In addition, five clusters were identified comprising exclusively $\mathrm{nBiX}$ genes. Four contained at least two protein-coding 
genes (Fig. 6a, cluster \#28-31), and one contained a protein coding gene and a ncRNA (Fig. 6a, cluster \#32). Neither of these clusters possessed a DMR within $250 \mathrm{~kb}$ or in the same TAD, but two clusters were associated with allele-specific H3K27me3 on the TSS of at least one cluster member. Three nBiX clusters were not associated with either DMRs or maternal H3K27me3.

\section{DISCUSSION}

345 By combining allele-specific transcriptomics and uniparental DNA methylome profiling, we have delineated the imprinting status of blastocyst-stage mouse embryos, identifying 859 parent-of-origin-specific DMRs and 106 genes with parent-of-origin-specific allelic bias (nBsX genes), and 71 novel imprinted genes with parent-of-origin-specific expression with an allelic ratio of 70:30 or greater (nBiX genes). Parental expression bias was evident in blastocysts for only 34 of 134 published imprinted genes and we detected statistically indistinguishable expression of both alleles for 24 published imprinted genes. Of those, four including Commd1 exhibited significant biallelic expression in blastocysts despite each having a DMR within their gene-bodies, showing that differential DNA methylation is not sufficient to guarantee uniparental expression. This suggests that hitherto unappreciated tissue- and stage-specified programmes underlie the regulation of imprinted gene expression.

Published imprinted genes represented in the BiX dataset exhibited different DNAmethylation profiles compared to published imprinted genes not showing significant parentof-origin-specific expression (Fig. 4b). This points to the existence of at least two broad classes of known imprinted genes: i) those with closely-associated DMRs, which are likely to 

less likely to exhibit parent-of-origin specific expression in blastocysts.

Many DNA methylation-based imprints are GL-DMRs, and most (55\%) of the DMRs we detected in blastocysts had indeed also been identified in gamete-specific DNA-methylation analysis. A further $41 \%$ of blastocyst DMRs were generated by parent-of-origin-specific loss of DNA methylation on one (mainly the paternal) parental allele. We also detected a gain of allele-specific DNA methylation at some loci that were unmethylated in gametes, suggesting that parent-of-origin specific DNA methylation in blastocysts can be encoded in gametes independently of DNA methylation and later decoded to allow DNA methylation during preimplantation development. DMRs with the exceptions of the Gnas and Liz1/Zdbf2 loci, at least within the passaging range ( 8 to 20 passages) used in our assays. We also observed a tendency for haploid, but not diploid ESCs to lose DMRs, in contrast to stable imprint maintenance in human haploid parthenogenetic ESCs ${ }^{48}$. Whether this difference in imprint stability in haploid ESCs reflects species, culture or cell state (e.g. naïve vs primed pluripotent) differences is unclear.

Our data also show that H3K27me3- and DMR-based imprinting mechanisms regulate overlapping but largely distinct gene sets. Indeed, some well-studied imprinted genes, including Airn, Snrf/Snrpn, Peg3, Fkbp6, Nespas, Kcnq1ot1 and Slc38a1 harbour both proximal DMRs and H3K27me3 peaks on their TSSs. However, imprinted expression of these genes is not necessarily directly dependent on H3K27me3; it depends on maternal Dnmt3I for Peg3, Nespas, Fkbp6 and Kcnq1ot1. This suggests that overlapping chromatin profiles of 
allele-differential DNA methylation and H3K27me3 do not always translate into functional redundancy and that additional layers of regulation exist that dictate dependence of imprinted expression on H3K27me3 or DMRs. control, such that a given ICR can regulate the expression of multiple genes. We identified five novel imprinted gene clusters and new members of multiple known clusters. All novel (and all expanded) clusters lacked blastocyst DMRs detected within $250 \mathrm{~kb}$ or present in the same TAD. Six out of the 10 'non-DMR clusters' contained at least one gene associated with $\mathrm{H} 3 \mathrm{~K} 27$ me3, suggesting that their imprinting is controlled via allele-specific PRC2 mediated histone modification at E4.5.

In sum, this work provides a detailed compendium that identifies novel imprinted genes and imprinting clusters. It reveals a major contribution of Polycomb mediated imprint control in blastocysts (Fig. 7), suggesting that imprint regulation in preimplantation embryos is

achieved by both H3K27me3- and DMR-dependent mechanisms. The implication is therefore that there exist different tiers of mechanistically distinguishable, potentially stagespecific imprinting that must be integrated for the healthy development of preimplantation embryos and beyond.

\section{AUTHOR CONTRIBUTIONS}

LS performed experiments and analysed data. FH performed biocomputational experiments and analysed data. FTT performed allele specific RNAseq analysis with support from FP and 
bioRxiv preprint doi: https://doi org/10.1101/202011.03.366948; this version posted November 5,2020 . The copyright holder for this preprint (which was not certified by peer review) is the author/funder, who has granted bioRxiv a license to display the preprint in perpetuity. It is made available under aCC-BY-NC-ND 4.0 International license.

SH. AB supervised RNAseq analysis. TS generated androgenetic and parthenogenetic embryos and performed 'semicloning' experiments. MA performed embryo immunofluorescence assays. MF and CB performed and supervised SMARTseq 2 and $\mu$ WGBS analysis. JR provided experimental support to LS. XM performed TAD analysis supervised by EDH. ACFP and ML conceived and supervised the study, provided funding an analysed data. ACFP and ML wrote the paper together with LS, FH and FTT with input from all authors. 
bioRxiv preprint doi: https://doi.org/10.1101/2020.11.03.366948; this version posted November 5, 2020. The copyright holder for this preprint (which not certified by peer review) is the author/funder, who has gr mted bioRxiv a license to display the preprint in

FW $९$ @ $@ \sigma^{\prime \prime} n=3$

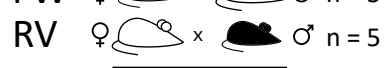

d

Parent-of-originspecific expression

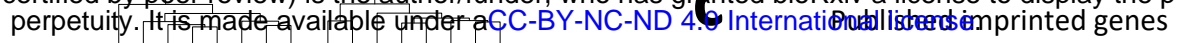
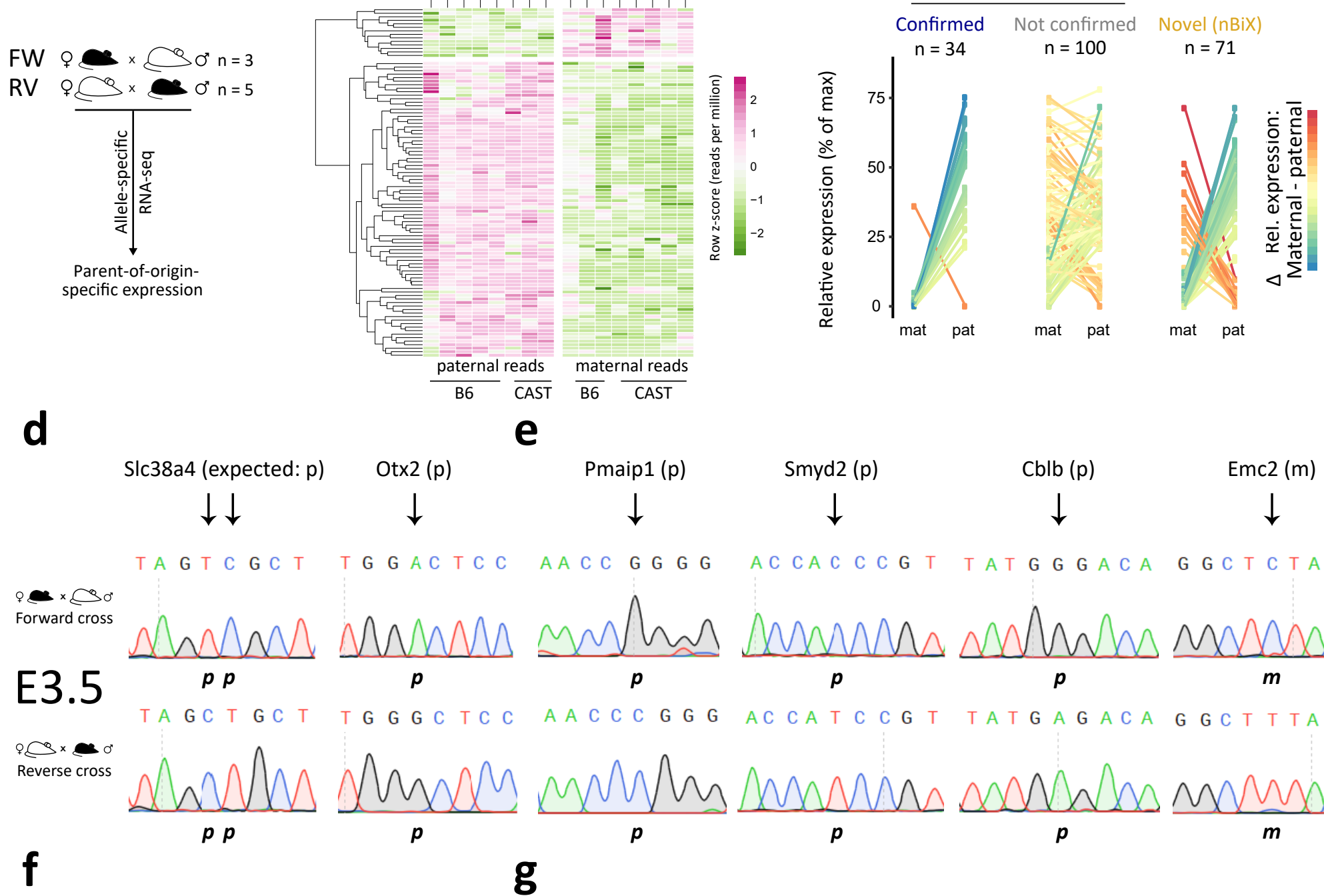

Slc38a4 (expected: $p) \quad$ Otx2 (p)

e

A G T C G C

T G G A C T C C A A C C G G G G

Pmaip1 (p)

Smyd2 (p)

Cblb (p)

$\operatorname{Emc2}(\mathrm{m})$

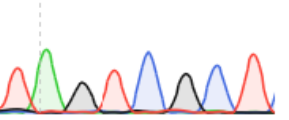

$p p$

TA G C T G C T T G G G C T C C

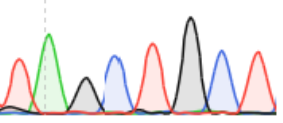

$p \boldsymbol{p}$

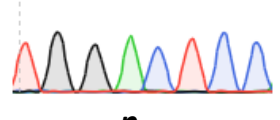

\section{p}

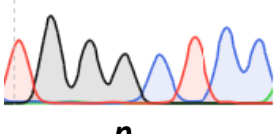

p

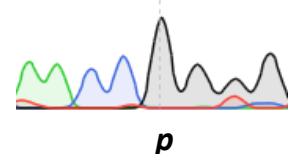

p

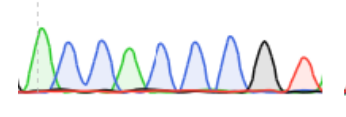

p m

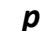

p

normons

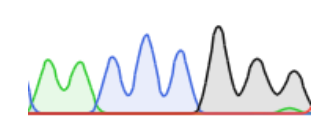

$p$

MAVMn

$p$

TA G T C G C T T G G RC TCC A A C C S G G G AC CA Y C C G T TATG RGACA G G C T Y T A CA

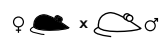

Forward cross

E6.5

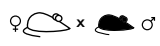

Reverse cross

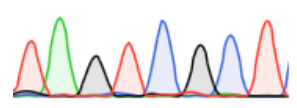

$p p$

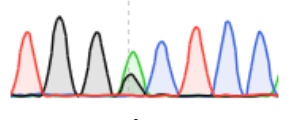

$m+p$

T A G C T G C T

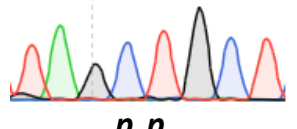

$p p$
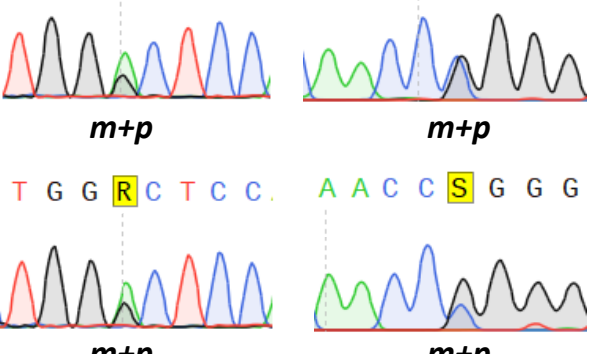

$m+p$

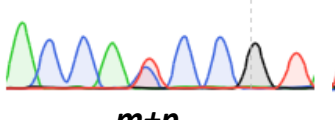

$m+p$

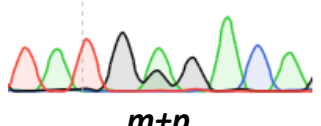

$m+p$

$m+p$
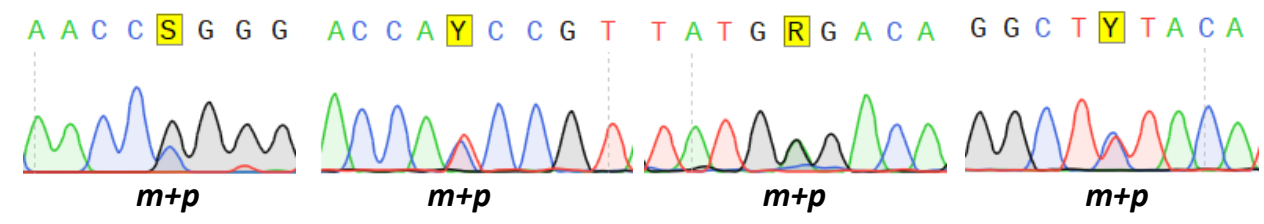

h

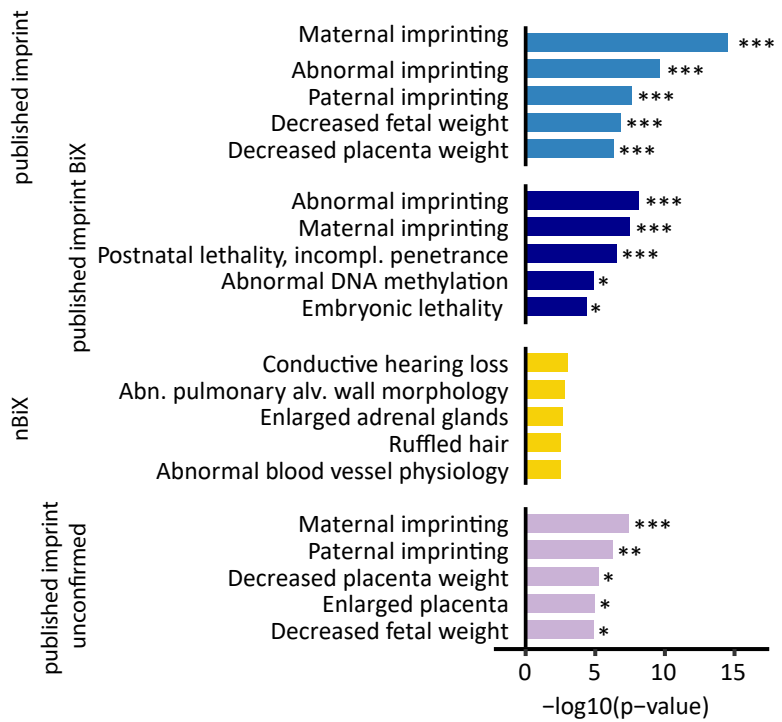

LOF expression from GEO

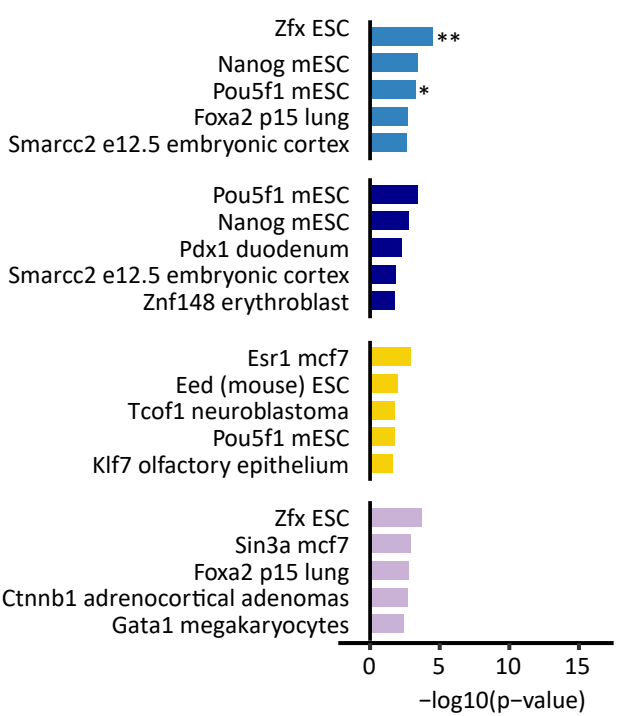



perpetuity. It is made available under aCC-BY-NC-ND 4.0 International license.

$$
\mathrm{nBsX}
$$

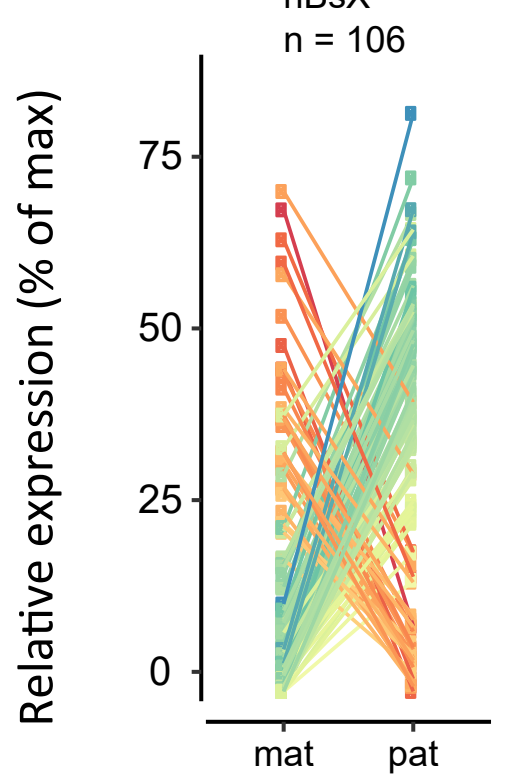

b

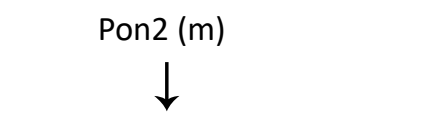

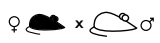

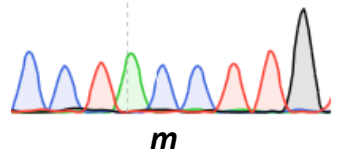

E3.5

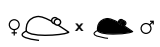

Reverse cross
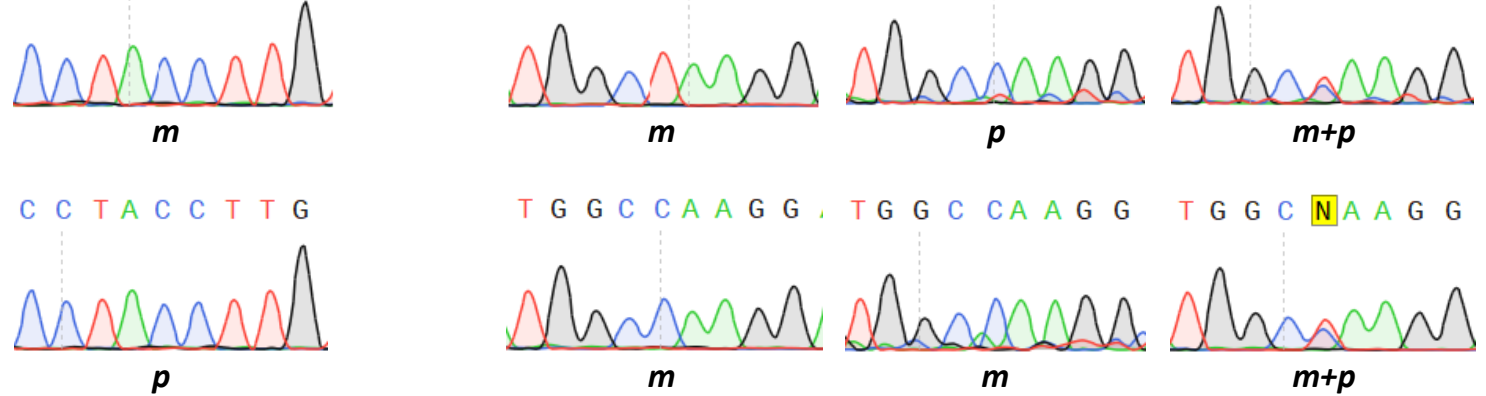

$T G G C C A A G G, T G G C C A A G G \quad T G G C N A A G G$

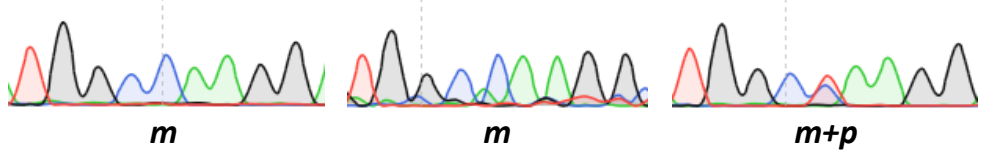

C
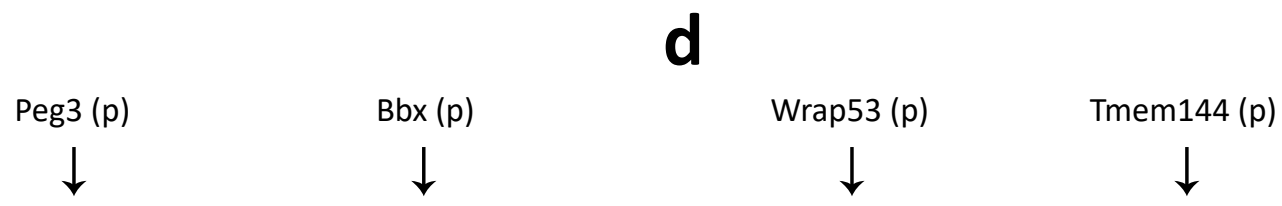

Sri (m)

C A T A C A G T T CA ACA T G A G

T T G A T G A C C

C T G T C T G T

A G C TACA G A

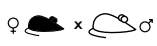

Forward cross

E

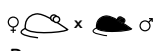

Reverse cross

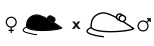

Forward cross

E6.5

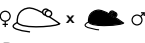

Reverse cross

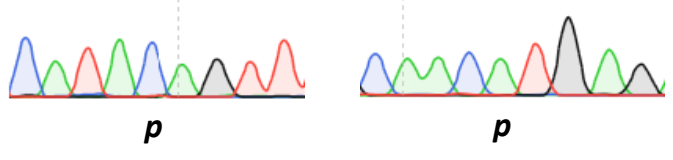

C A T A T A G T T C A A C G T G A G

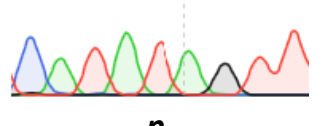

$\boldsymbol{p}$

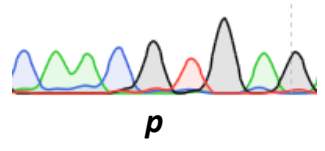

C A A C R T G A G

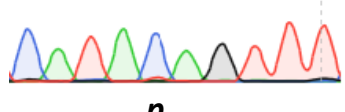

$p$

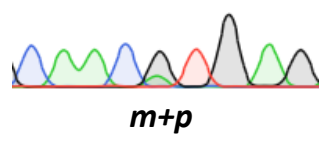

C A T A T A G T T T

C A A C R T G A G axman

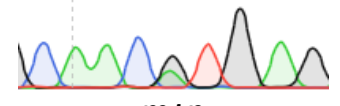

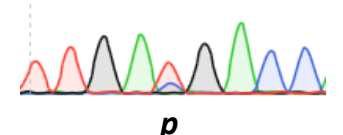

T T G A C G A C C
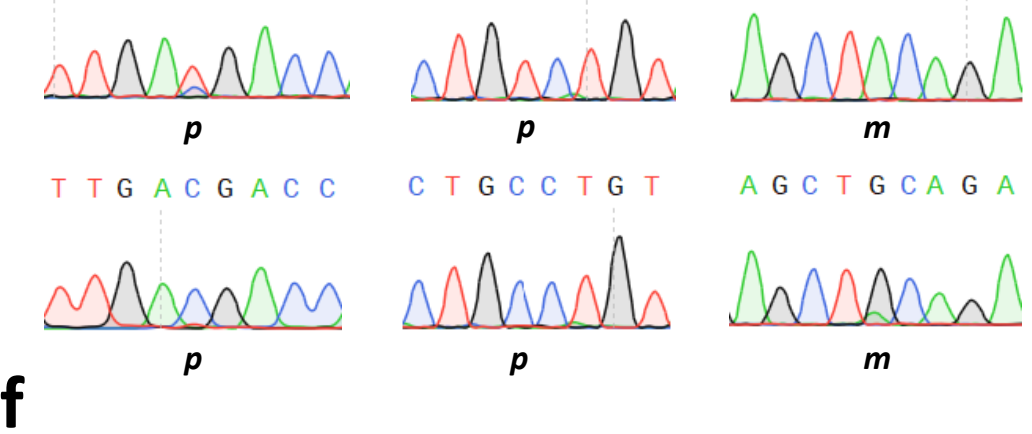

$A G C T G C A G A$

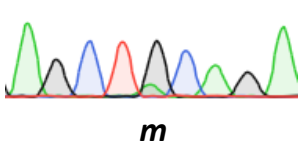

$T T G A Y G A C C \quad C \quad T G Y C T G T$

A G C T R A G A
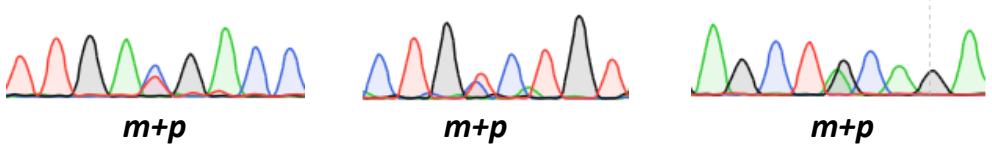

$T$ T G A Y G A C C

C $T$ G $\mathrm{Y}$ C $T$ T G T

$A G C T R C A G A$

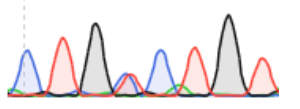

$m+p$

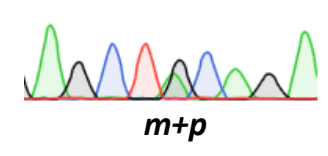




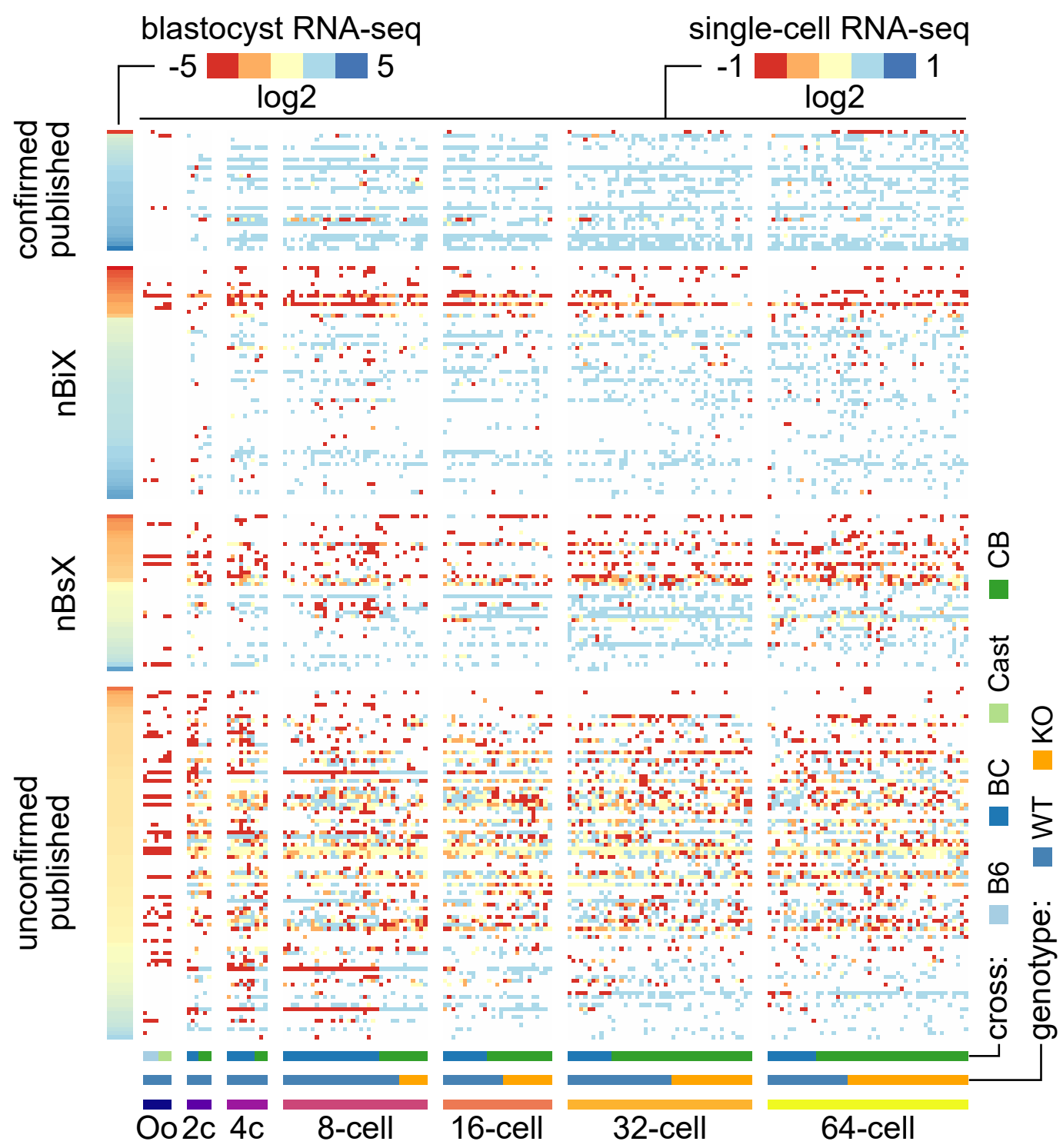

h

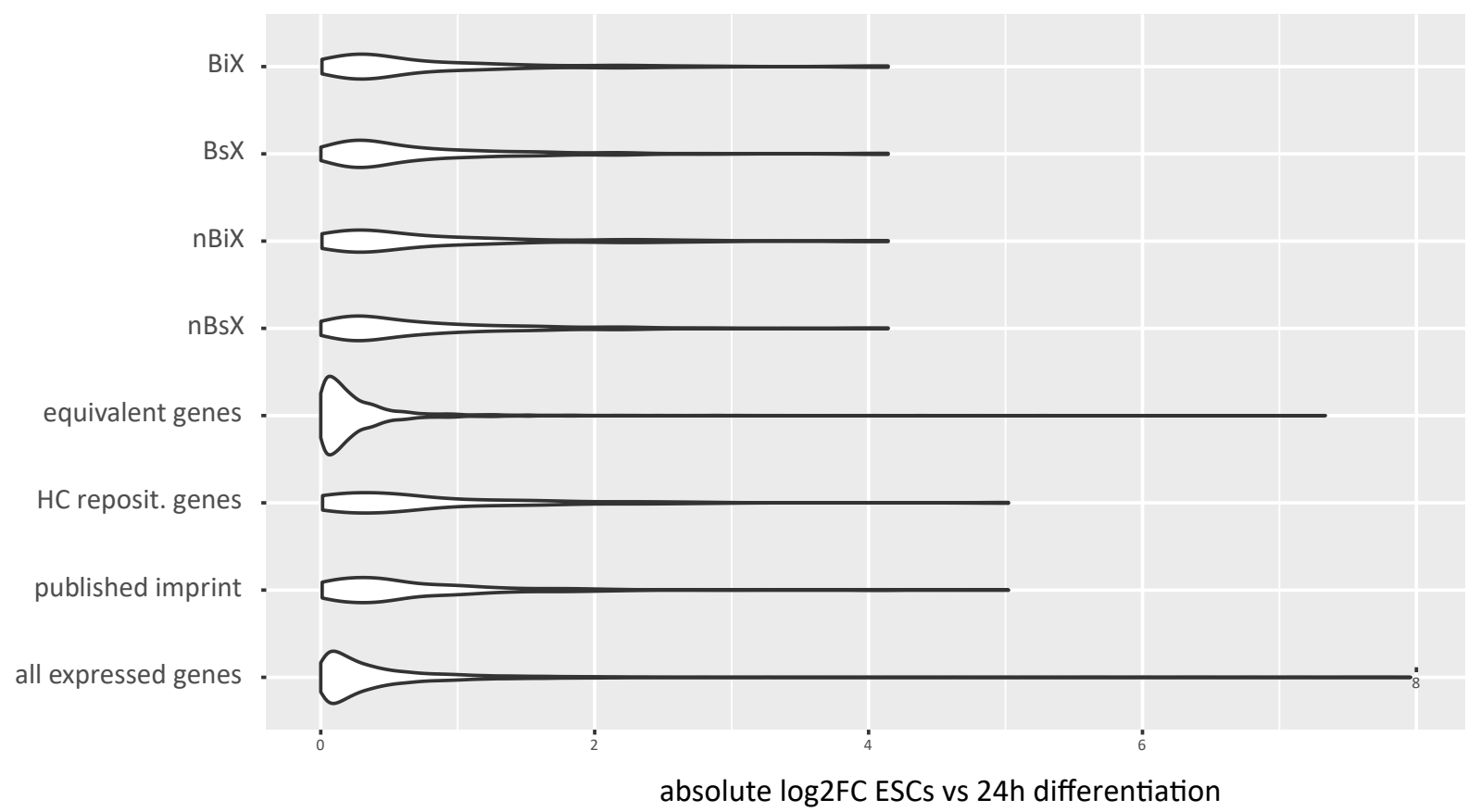


bioRxiv preprint doi: https://doi.org/10.1101/2020.11.03.366948; this version posted November 5, 2020. The copyright holder for this preprint (which was not certified by peer review) is the author/funder, who has granted bioRxiv a license to display the preprint in

a

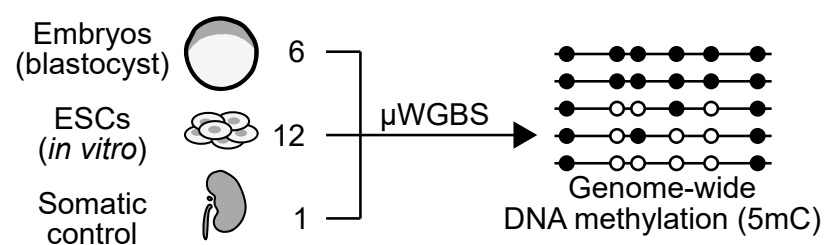

\section{b}
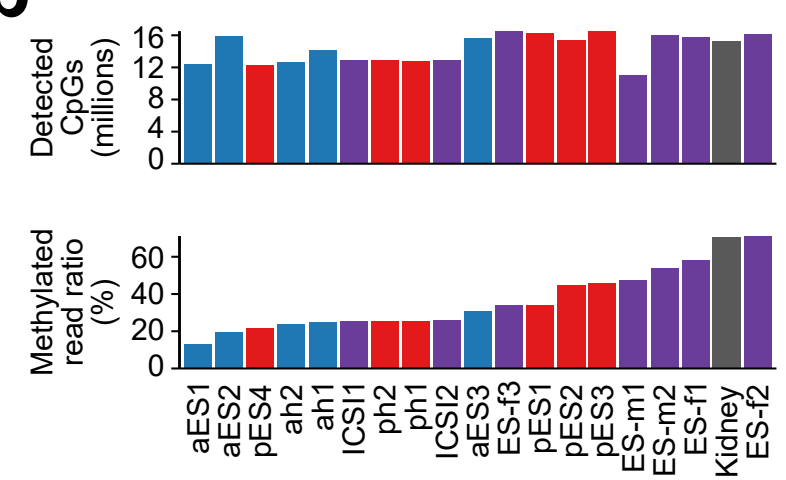

Biparental $\square$ Parthenogenote (ph) $\square$ Androgenote (ah)

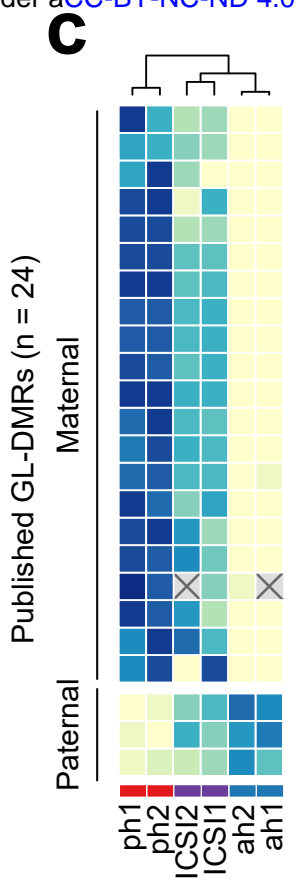

Embryos

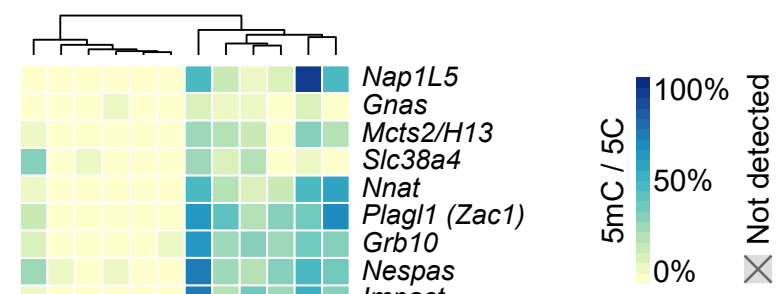

Impact

Mest (Peg1)

Konq1

Kcnq1ot1

$\operatorname{lgf} 2 r$

Cdh15

Inpp5f

Zim2 (Peg3)

KcnK9 (Peg13)

Snrpn

Commd1

Peg10

Liz1/Zdbf2

H19/lgf2

Dlk1-Dio3

Rasgrf1

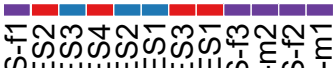

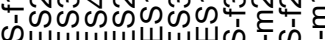

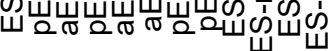

Embryonic stem cells 
bioRxiv preprint doi: https://doi.org/10.1101/2020.11.03.366948; this version posted November 5, 2020. The copyright holder for this

a preprint (whieswwas not certified by peepreview) is the atthor/fypder, whg has granted bioRxiv a license to display the preprint in
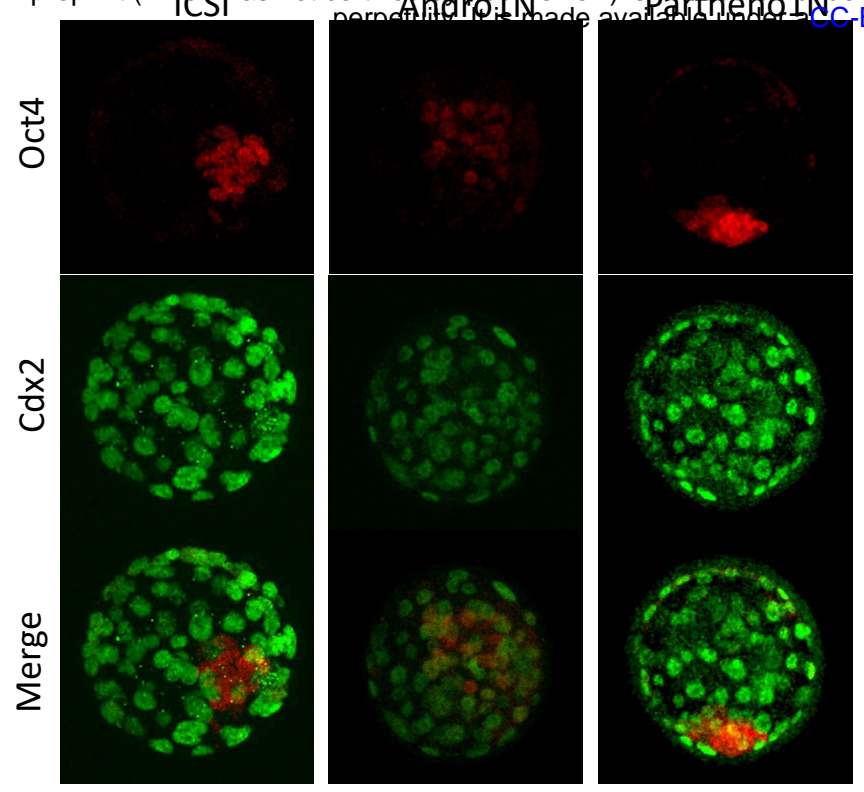

ND 4.0 International license.

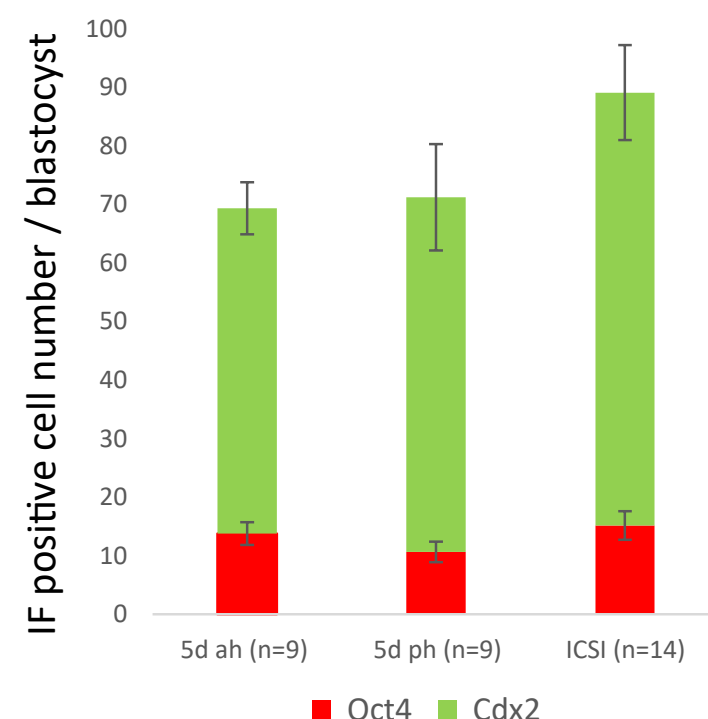

C

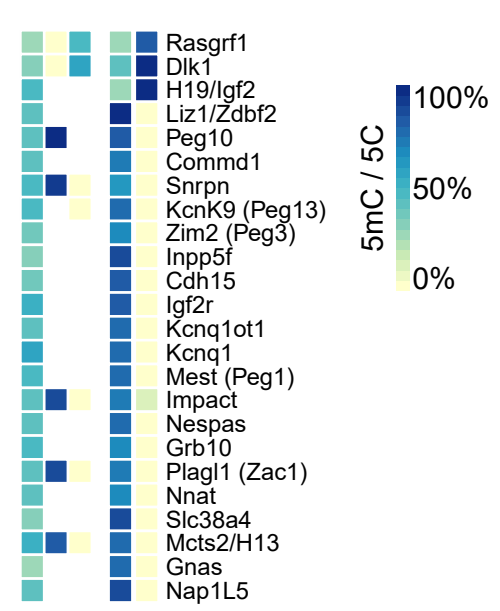

d

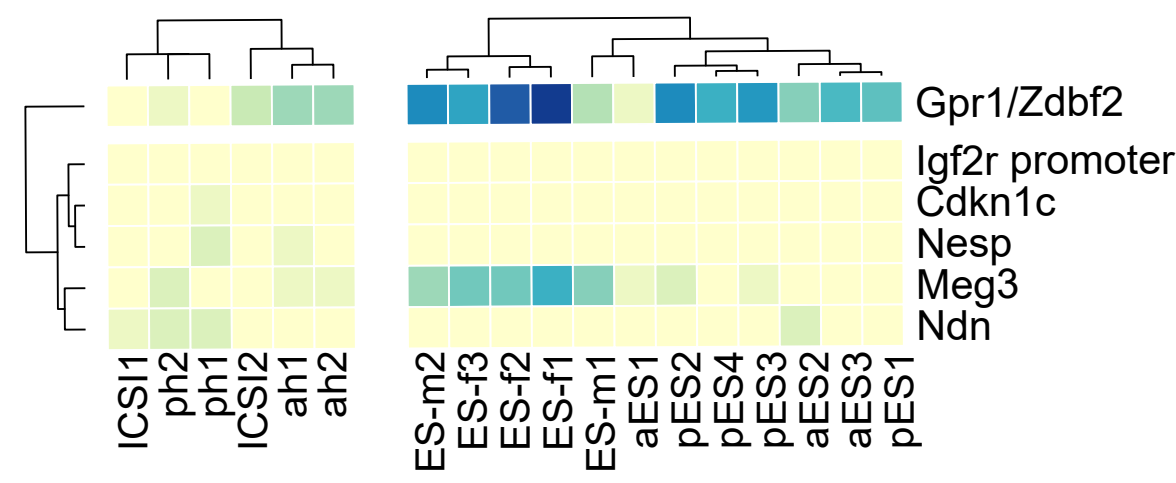

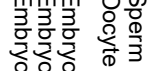

उฺุ

e
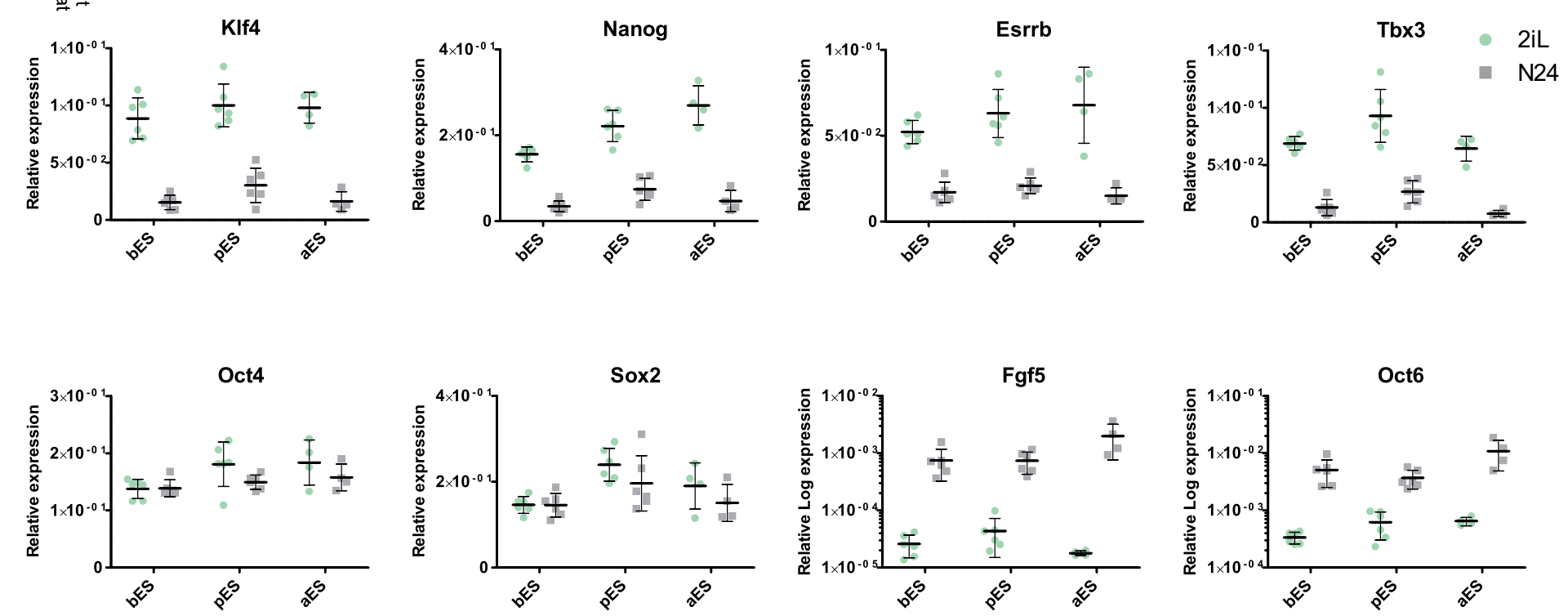

$f$
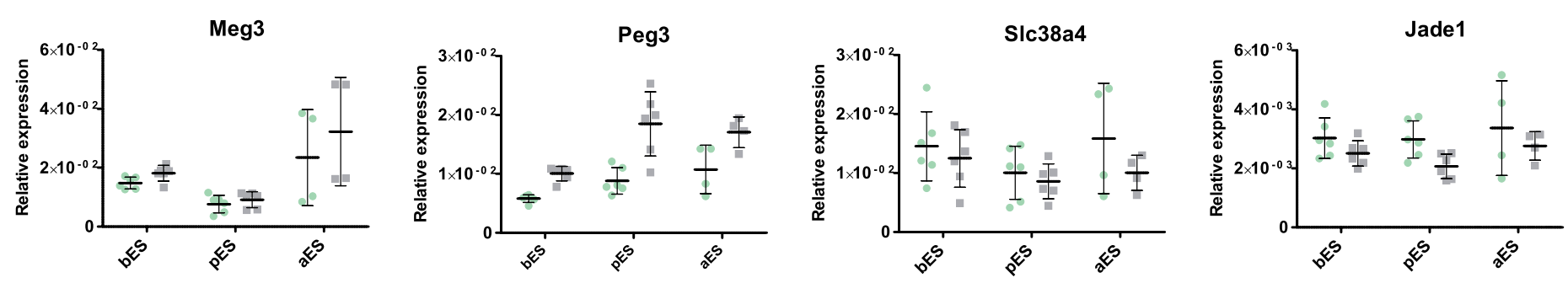

Extended Data Figure 2 
bioRxiv preprint doi: https://doi.org/10.1101/2020.11.03.366948; this version posted November 5, 2020. The copyright holder for this preprint (which was not certified by peer review) is the author/funder, who has granted bioRxiv a license to display the preprint in perpetuity. It is made available under aCC-BY-NC-ND 4.0 International license.

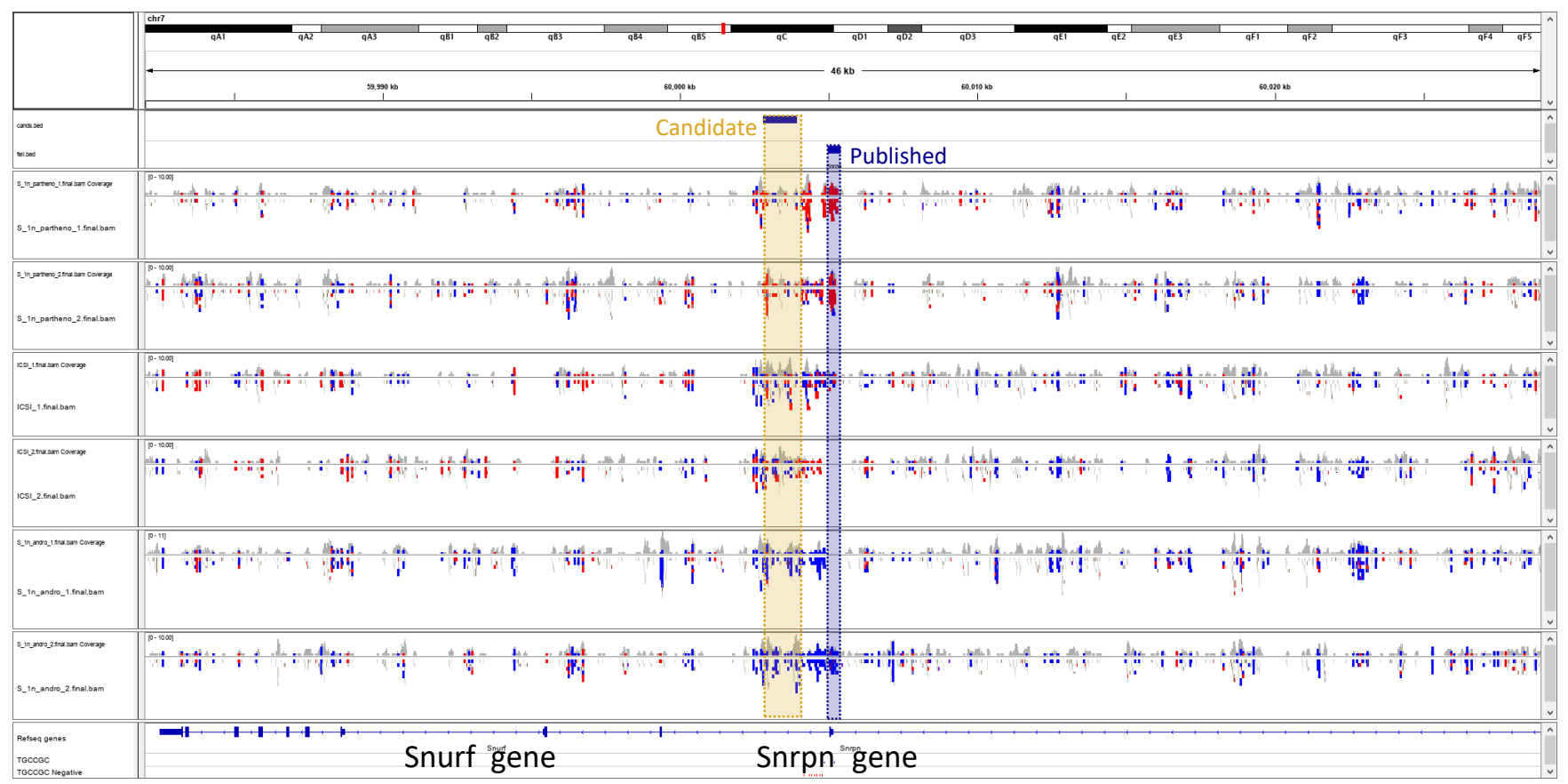

b

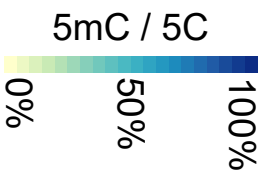
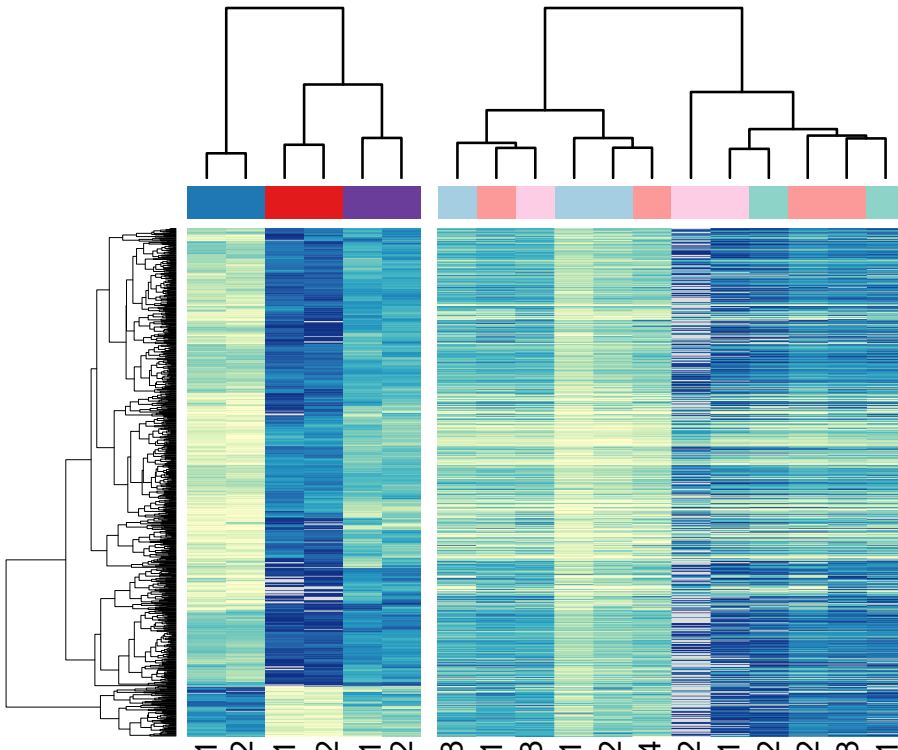

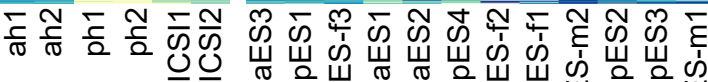

C

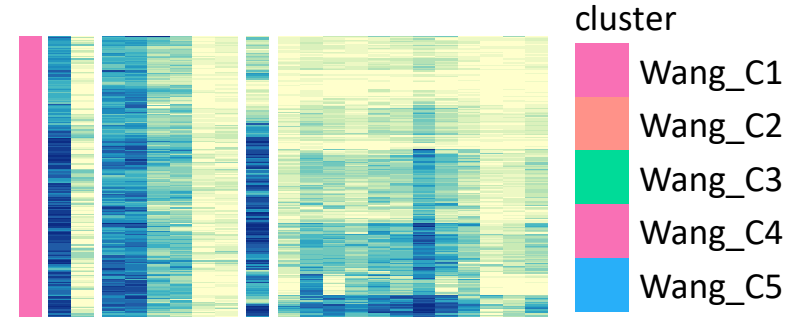




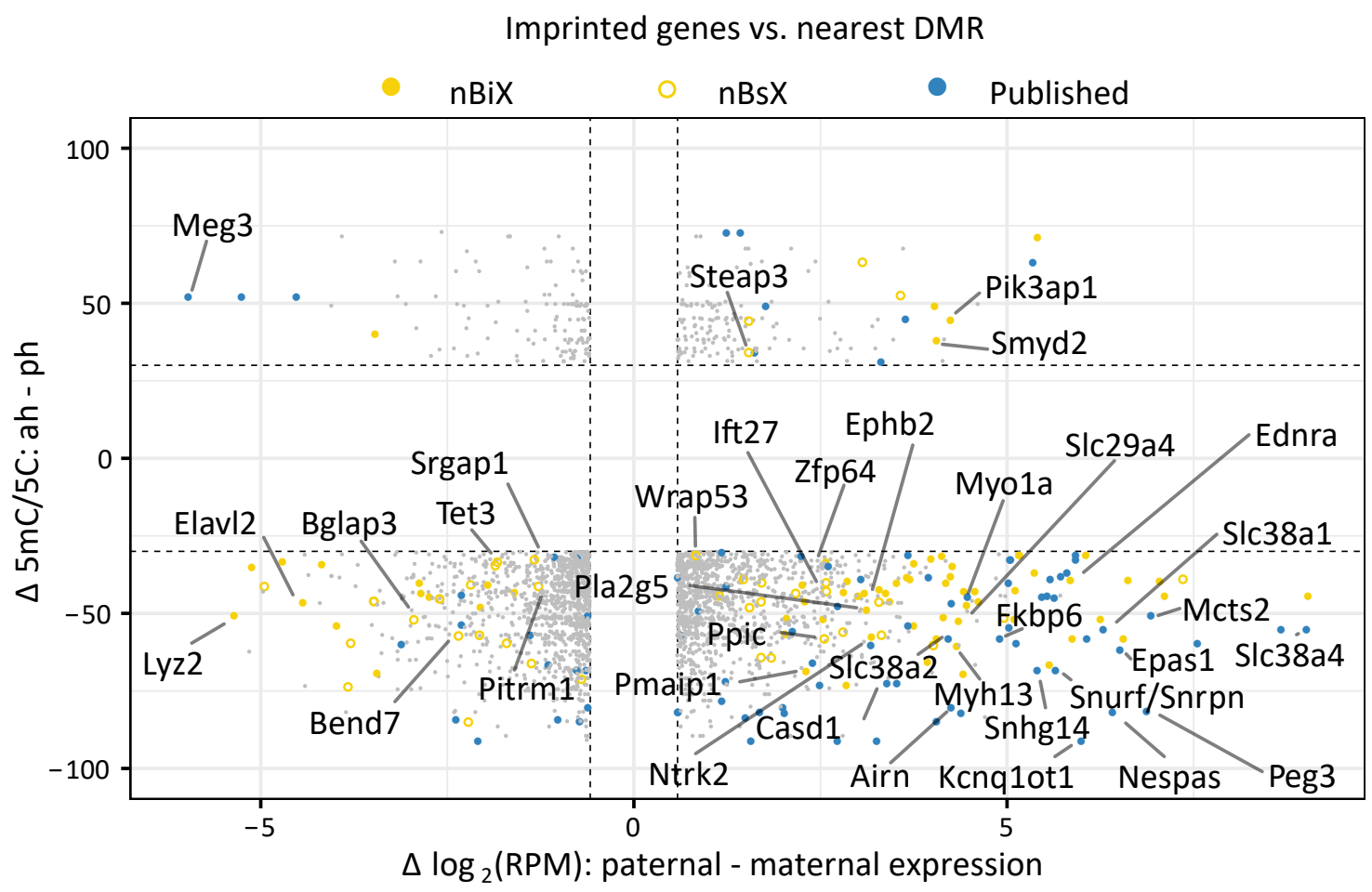

All expressed genes

$$
n=10743
$$

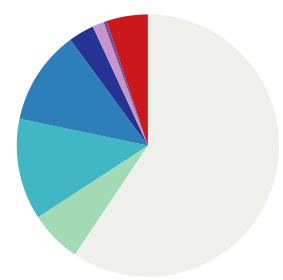

Confirmed published imprints $\mathrm{n}=34$

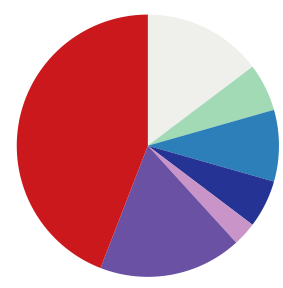

nBiXs $n=71$

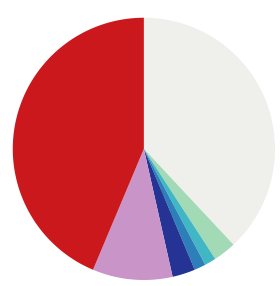

Published imprints

$$
n=134
$$

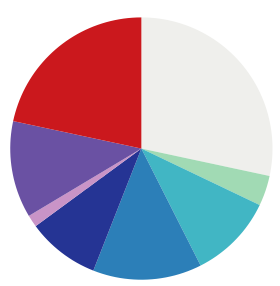

Unconfirmed published imprints

$$
n=100
$$

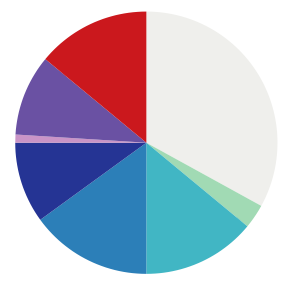

nBsXs

$n=106$

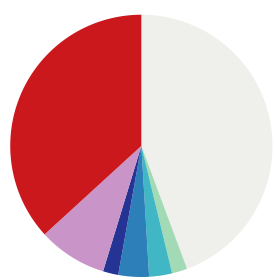

High confidence repository imprints

$\mathrm{n}=30$

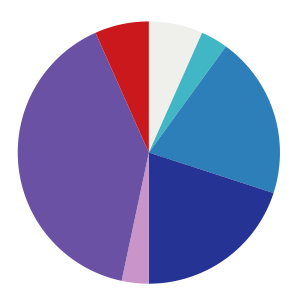

Genes with equivalent expression from both alleles

$$
\mathrm{n}=\sim 5,000
$$

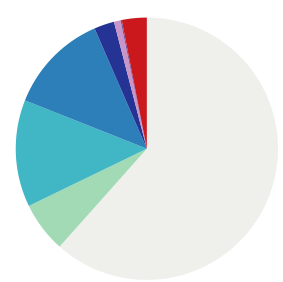



perpetuity. It is made available under aCC-BY-NC-ND 4.0 International license.

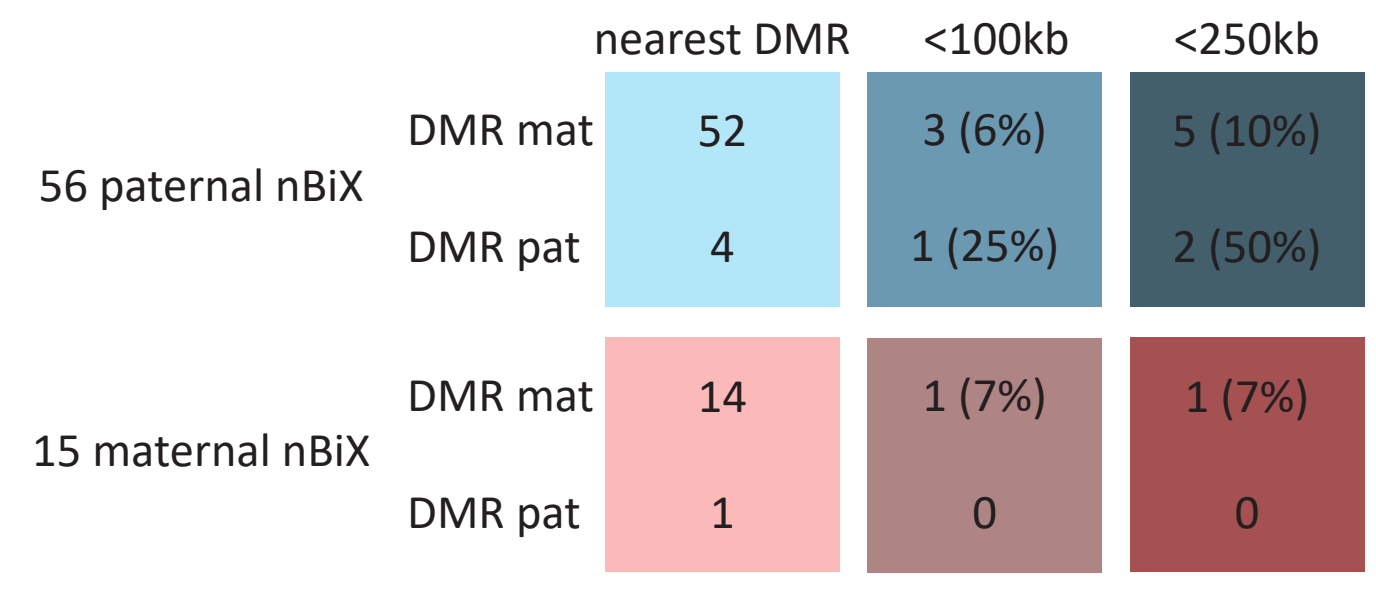

b

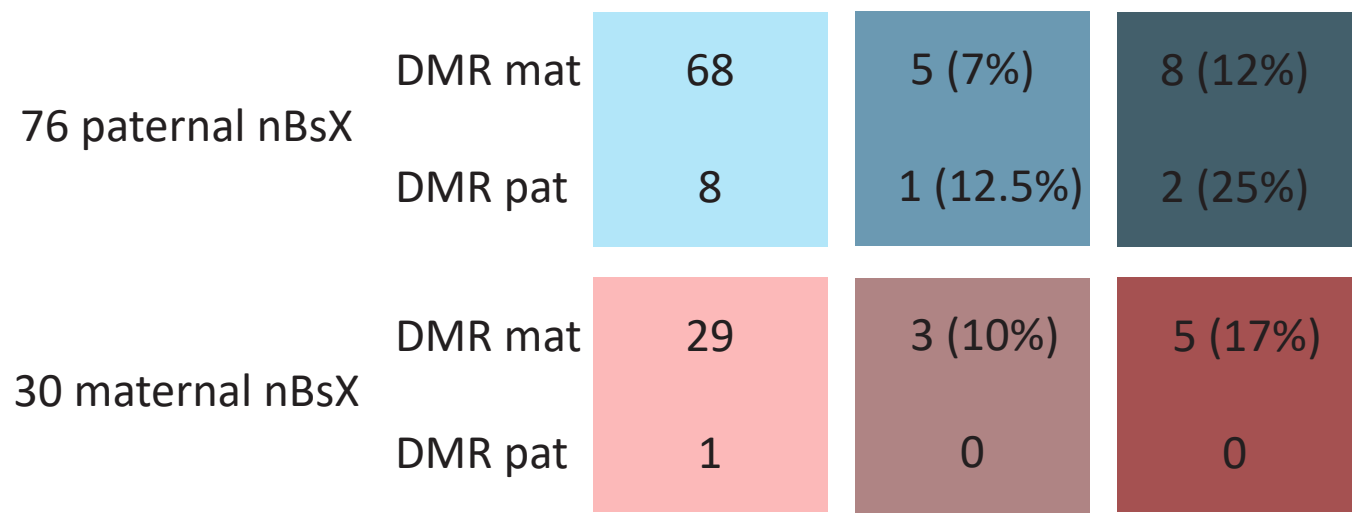

C

high confidence repository imprinted genes sharing TAD with DMR $(n=30)$

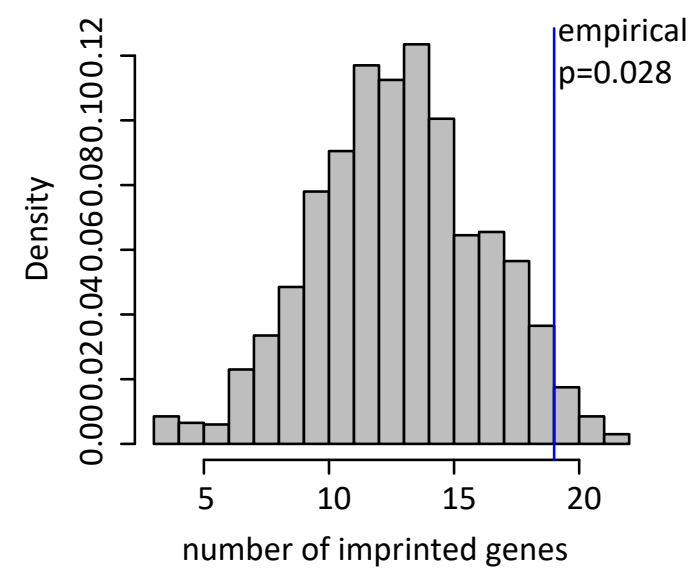

d
nBiXs

27

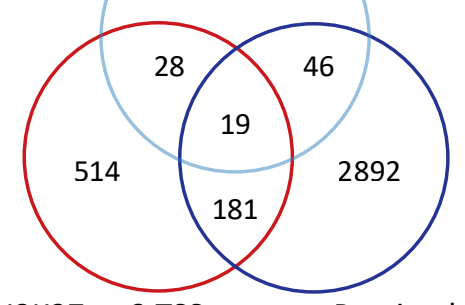

$\mathrm{nBiX}$

sharing TAD with DMR ( $n=71)$

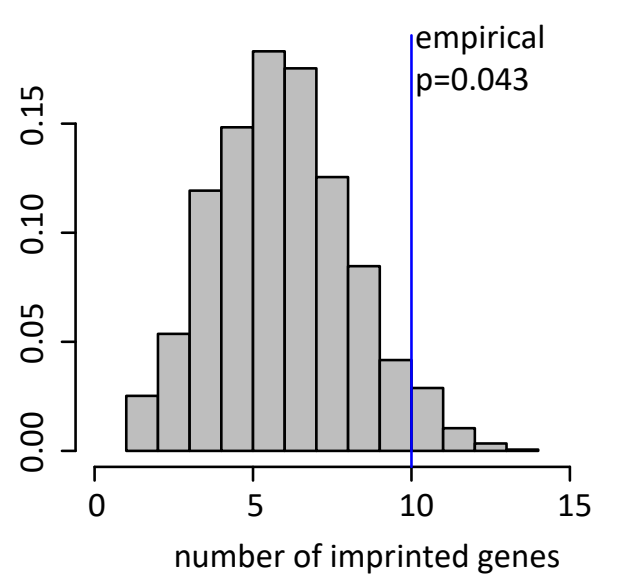

equivalent genes sharing TAD with DMR ( $n=4 k$ )

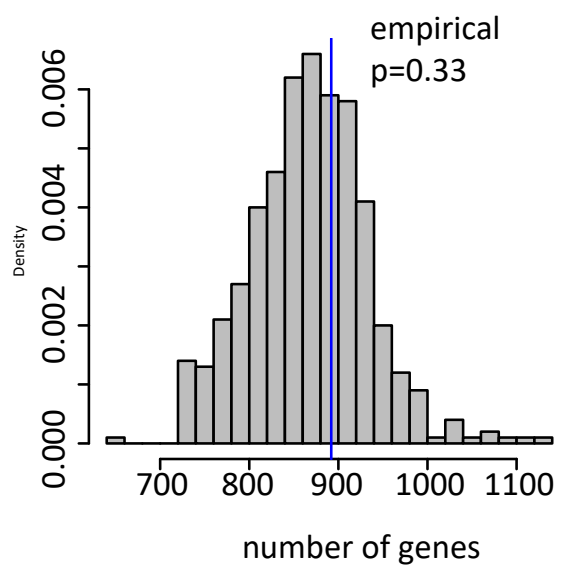

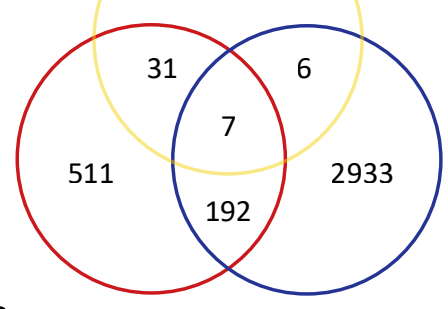
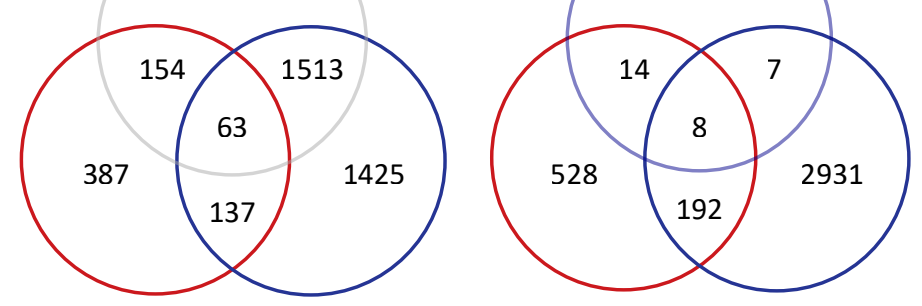
bioRxiv preprint doi: https://doi org/10.1101/2020.11.03.366948; this version posted November 5,2020 . The copyright holder for this preprint (which was not certified by peer review) is the author/funder, who has granted bioRxiv a license to display the preprint in

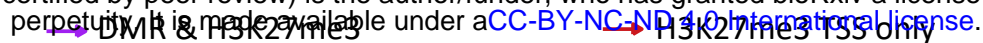

$\rightarrow$ DMR $<250 \mathrm{~kb}$ or same TAD only $\longrightarrow$ no mark
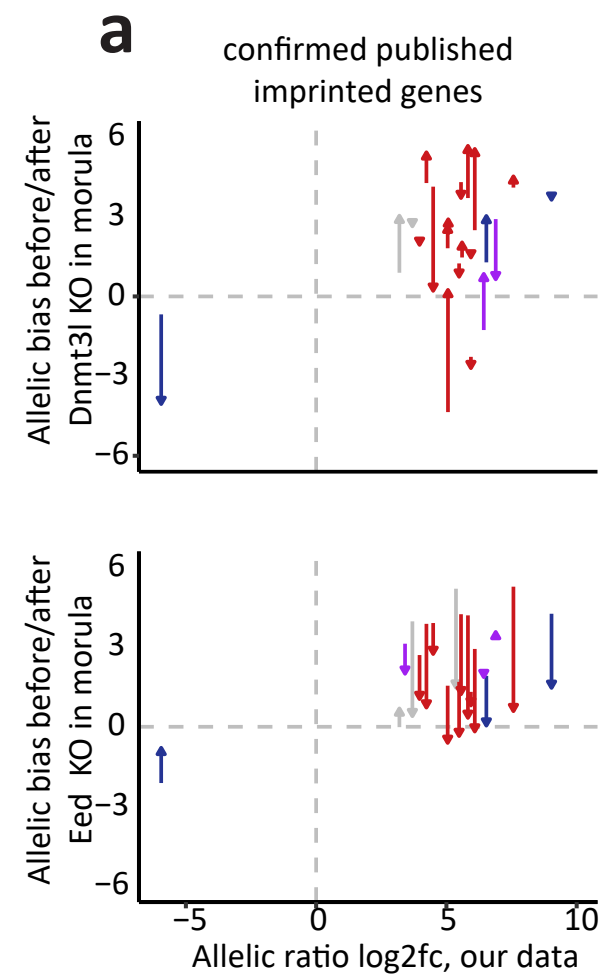

Q

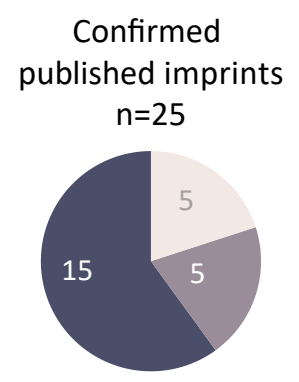

Unconfirmed published imprints $n=32$

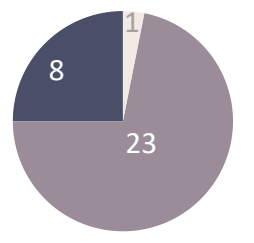

nBiXs

nBsXs

$\mathrm{n}=31$

$n=52$
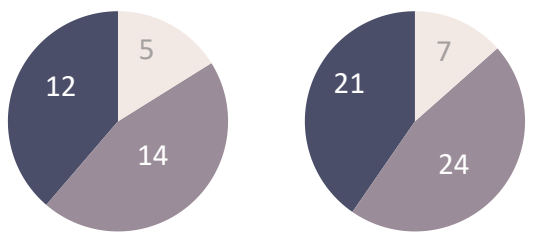

f

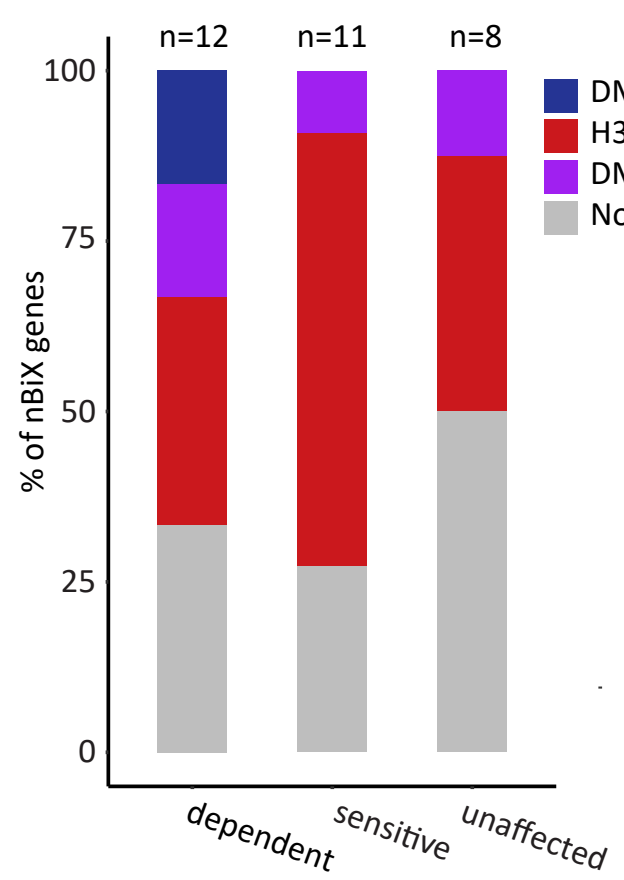

b unconfirmed published imprinted genes
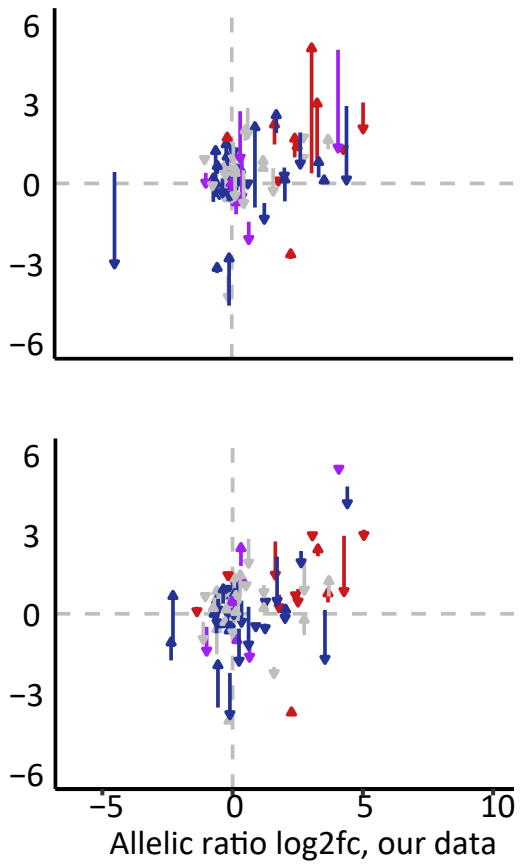

e

Equivalent genes

$\mathrm{n}=994$

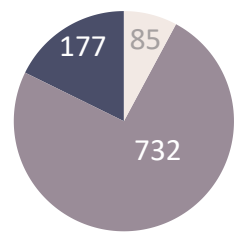

Dependent on Dnmt3I/H3K27me3 Independent

Not detected in one dataset

DMR $<250 \mathrm{~kb}$ or same TAD

H3K27me3 TSS

DMR $<250 \mathrm{~kb}$ or same TAD \& H3K27me3 No mark
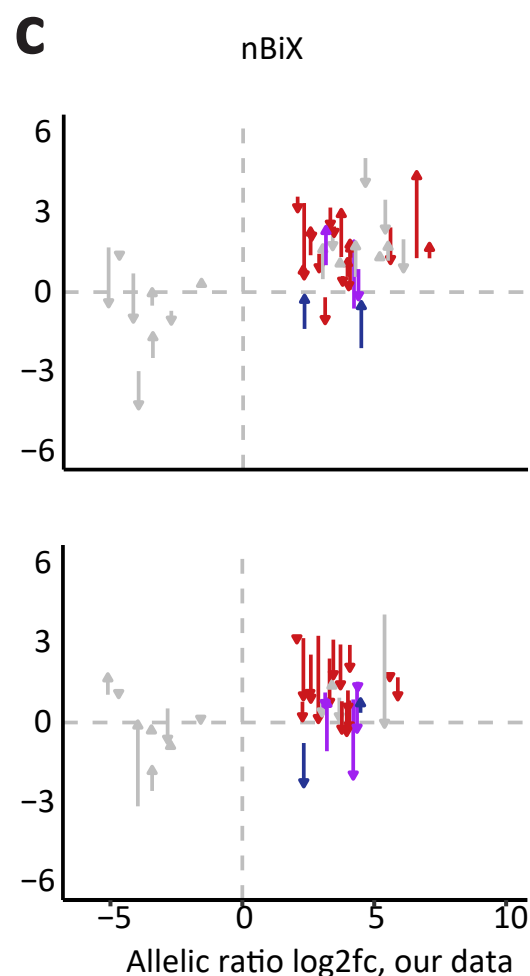

mDntm3I mEed
WT KO WT KO

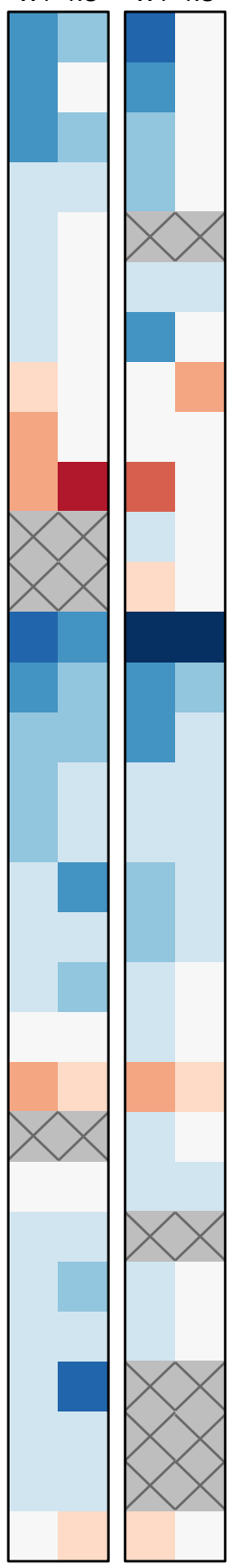

Sall1

Aard

App

Abca1

Abcc4

Thrsp

Bend4

Pmaip1

Myo1a

Rab38

Myh13

Ntrk2

Ly6c1

Cd109

Ly6f

Ispd

Bin1

Zfp2

Cblb

Pla2g5

Tcf4

Nav3

Zfp202

Slc29a4

\section{Not detected}

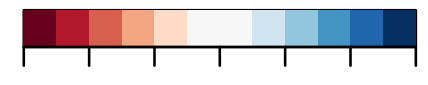

$\begin{array}{lllllll}-6 & -4 & -2 & 0 & 2 & 4 & 6\end{array}$

Allelic bias

nBiX dependent

on Dnmt3l

and/or H3K27me3

nBiX sensitive

to Dnmt3l

and/or H3K27me3

\section{-OC105245869}

Fez2

Grin3a 
bioRxiv preprint doi: https://doi.org/10.1101/2020.11 03.366948; this version posted November 5, 2020. The copyright holder for this preprint (which was not certified by peer review) is the author/funder, who has granted bioRxiv a license to display the preprint in perpetuity. It is made available under aCC-BY-NC-ND 4.0 International license.

Confirmed published imprints

9

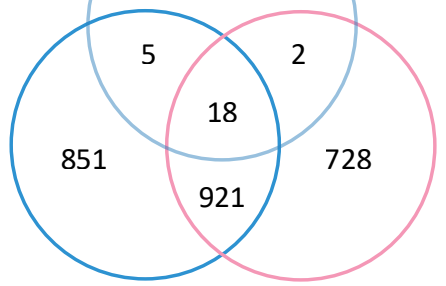

Imprinted-like in mDnmt3/ WT morulae

(Chen et al., 2019)
Unconfirmed published imprints

68

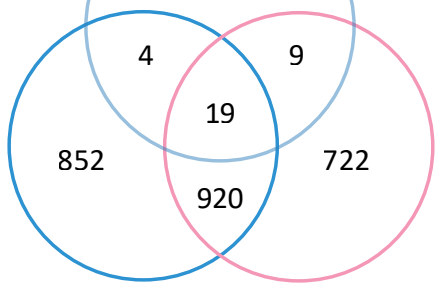

Imprinted-like in mEed WT morulae (Inoue et al., 2018)
Equivalent genes

4382

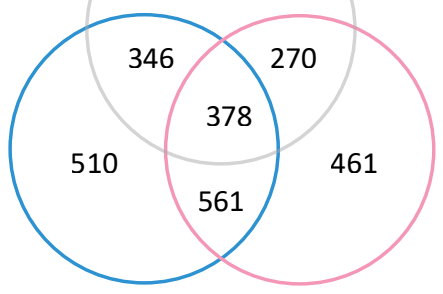

nBiXs

40

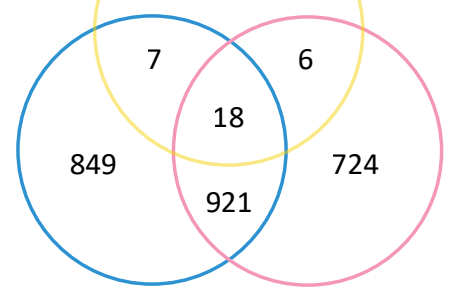

nBsXs

54

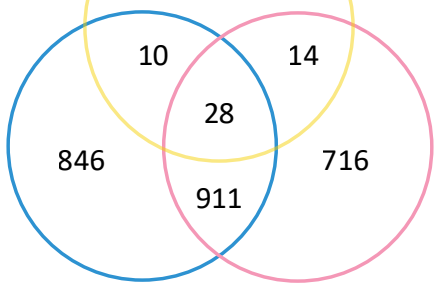

b

Confirmed published imprints $\mathrm{n}=25$

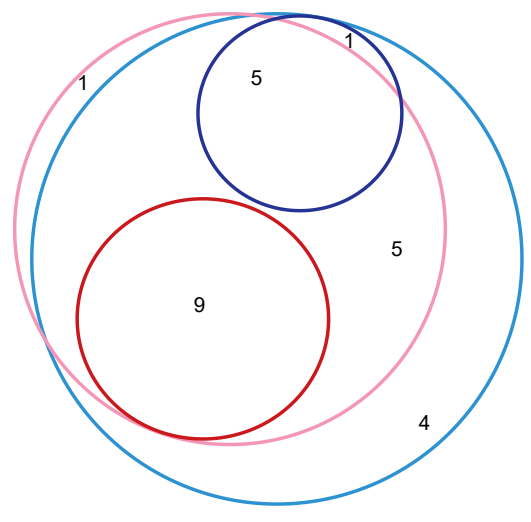

nBiXs

$n=31$

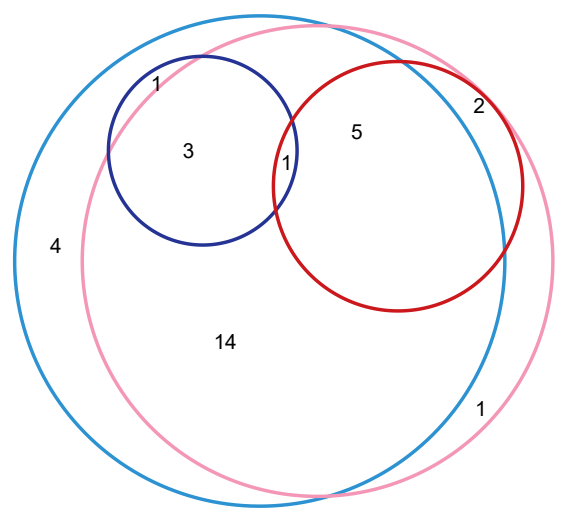

Unconfirmed published imprints $\mathrm{n}=32$

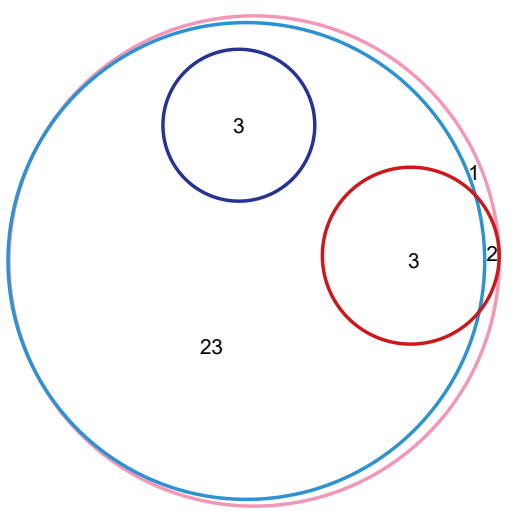

$\mathrm{nBsXs}$

$\mathrm{n}=52$
Equivalent genes $\mathrm{n}=994$

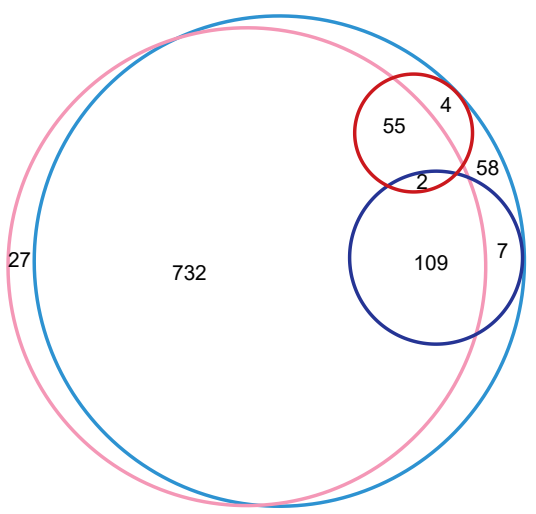

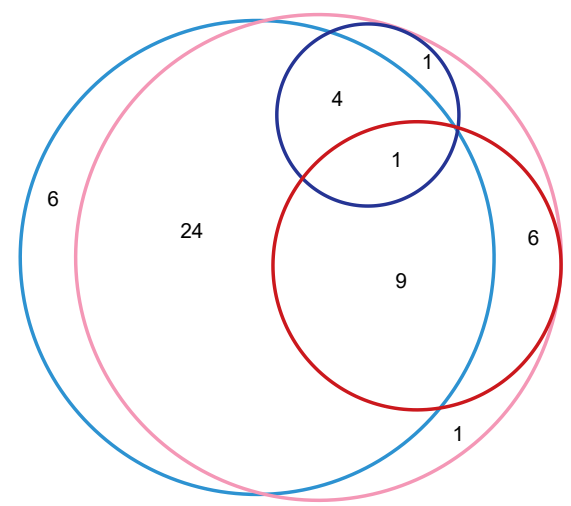


bioRxiv preprint doi: https://doi.org/10.1101/2020.11.03.366948; this version posted November 5, 2020. The copyright holder for this preprint (which was not certified by peer review) is the author/funder, who has granted bioRxiv a license to display the preprint in

c perpetuity. It is made available under aCC-BY-NC-ND 4.0 International license.

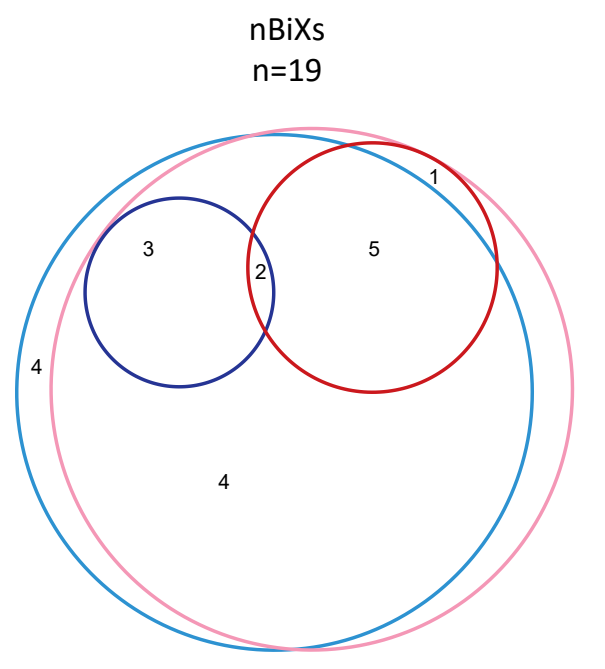

Confirmed published imprints $\mathrm{n}=25$

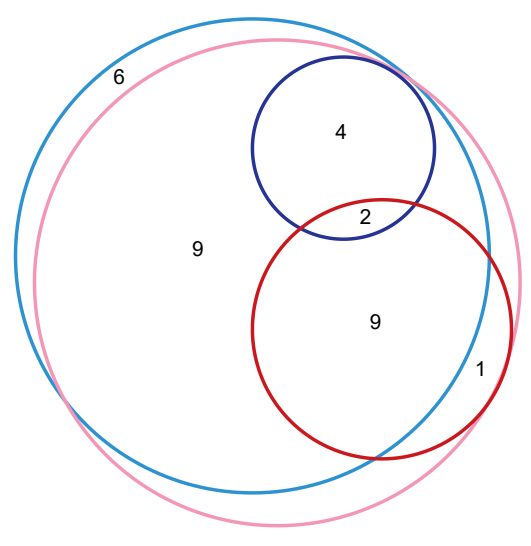

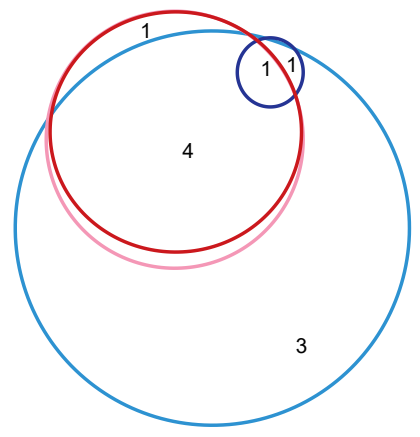

Dependent on H3K27me3

O Dependent on Dnmt3I

Imprinted-like in mEed WT morulae

imprinted-like in $\mathrm{mDnmt3}$ / WT morulae 
bioRxiv preprint doi: https://doi.org/10.1101/2020.11.03.366948; this version posted November 5,2020 . The copyright holder for this preprint (which was not certified by peer review) is the author/funder, who has granted bioRxiv a license to display the preprint in perpetuity. It is made available under aCC-BY-NC-ND 4.0 International license.

\begin{tabular}{|c|c|c|c|}
\hline Cluster\# & Genes & Nearest DMR & Distance to nearest DMR (bp) \\
\hline 1 & Eef1b2, Zdbf2 & r277 & 1420304 \\
\hline 2 & Meg3, $\underline{\text { Rtl11}}, \underline{\text { Rian }}$ & r1196 & 6974 \\
\hline 3 & Slc38a1, Slc38a2 & r494 & 349158 \\
\hline 4 & Igf2r, Airn & r27 & 0 \\
\hline 5 & Sfmbt2, Mir669d & r836 & 3287743 \\
\hline 6 & $\underline{\mathrm{H} 13}, \mathrm{Mcts} 2, \underline{\mathrm{Id} 1}, \underline{\mathrm{Bcl} 2 \mathrm{I} 1}, \underline{\mathrm{Tp} x 2}$ & r205, r869 & 0 \\
\hline 7 & Zfp64, 1700017J07Rik & r294, r545 & 0 \\
\hline 8 & Stx16, Npepl1, Nespas, Gnas & r2 & 0 \\
\hline 9 & Platr4, 2400006E01Rik, Jade1 & r180 & 742648 \\
\hline 10 & Peg3, Usp29 & r147 & 0 \\
\hline 11 & Snhg14, Snurf/Snrpn & r1173 & 0 \\
\hline 12 & Cd81, Tssc4, Kcnq1ot1, Nap1l4, Tnfrsf22, $\underline{\text { Tnfrsf23 }}$, Osbpl5, Dhcr7 & r25 & 0 \\
\hline 13 & Plag|1, Phactr2 & r36 & 0 \\
\hline 14 & $\underline{\text { Ddc, }}, \underline{\text { Grb10, }}$ Cobl & r111, r3 & 0 \\
\hline 15 & B3gnt2, Commd1, Zrsr1 & r19 & 0 \\
\hline 16 & Ppp2r5c, Dync1h1 & r387 & 0 \\
\hline 17 & Trappc9, Chrac1, Ago2 & r7 & 0 \\
\hline 18 & Tnfrsf9, Camta1 & r388, r502 & 0 \\
\hline 19 & Ppp1r9a, Pon2, Asb4 & r30, r196 & 0 \\
\hline 20 & Mest, Copg2 & r20 & 0 \\
\hline 21 & $\underline{B a g 3}, \underline{\operatorname{Inpp} 5 f}$ & r556 & 0 \\
\hline 22 & $\operatorname{lgf} 2, \operatorname{lgf} 20 \mathrm{~s}$ & r411 & 67908 \\
\hline 23 & Adamts2, Zfp2, 9230009102Rik, Platr20 & r364 & 366462 \\
\hline 24 & E2f3, Mboat1 & r1334 & 3884905 \\
\hline 25 & Sox21, LOC105245869, Abcc4 & r407 & 2545733 \\
\hline 26 & Tmem144, Fam198b & r616 & 3686913 \\
\hline 27 & Zfp202, Gramd1b & r649 & 1437493 \\
\hline 28 & Dap, Ankrd33b & r668 & 3470403 \\
\hline 29 & Ly6e, Ly6c1, Ly6f & r37 & 611245 \\
\hline 30 & Pter, Rsu1 & r836 & 5841340 \\
\hline 31 & KIk7, Klk5 & r105 & 987017 \\
\hline 32 & Bend4, C330024D21Rik & r1049 & 919981 \\
\hline
\end{tabular}

\section{TABLE LEGEND}

Novel parent-of-origin specific expressed gene (nBiX or $\mathrm{nBsX}$ )

$n C R N A$

Unconfirmed published imprinted gene

DMR within $250 \mathrm{~kb}$ or in same TAD

H3K27me3 TSS

DMR within $250 \mathrm{~kb}$ or in same TAD \& H3K27me3 TSS 
bioRxiv preprint doi: https://doi.org/10.1101/2020.11.03.366948; this version posted November 5, 2020. The copyright holder for this preprint (which was not certified by peer review) is the author/funder, who has granted bioRxiv a license to display the preprint in 3 perpetuity. It is made available under aCC-BY-NC-ND ${ }_{5}^{4} .0$ International license.
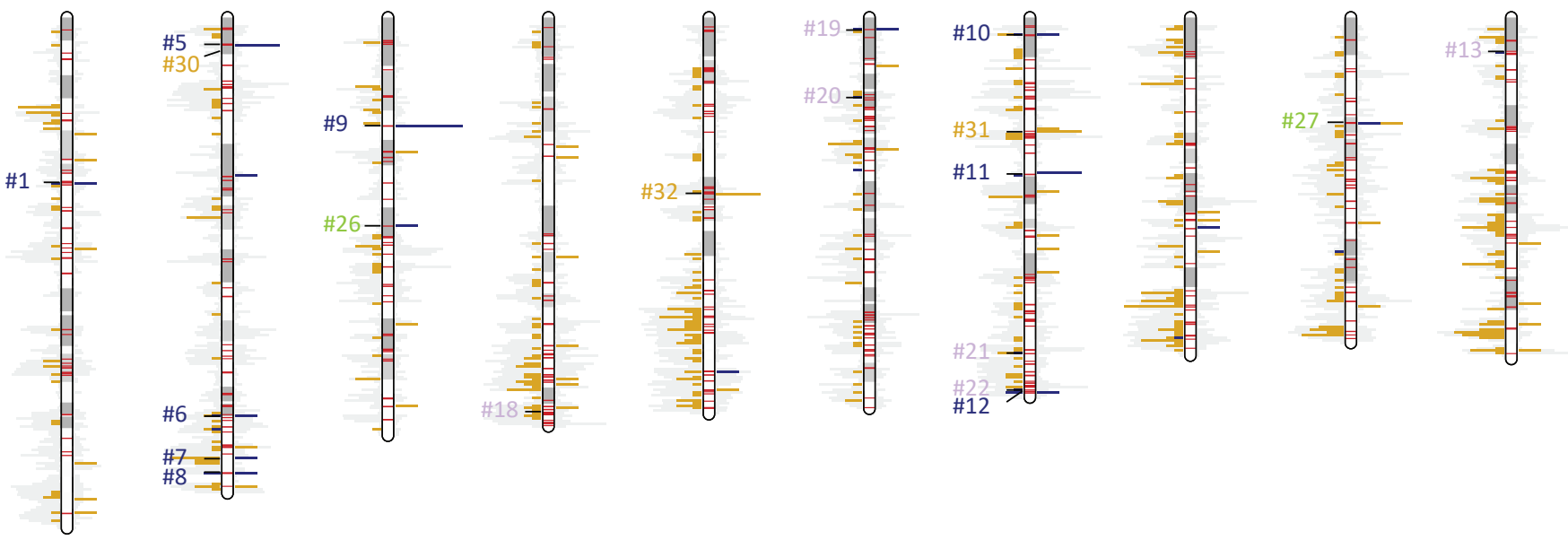

11

12

13

14

15

16

17

18

19
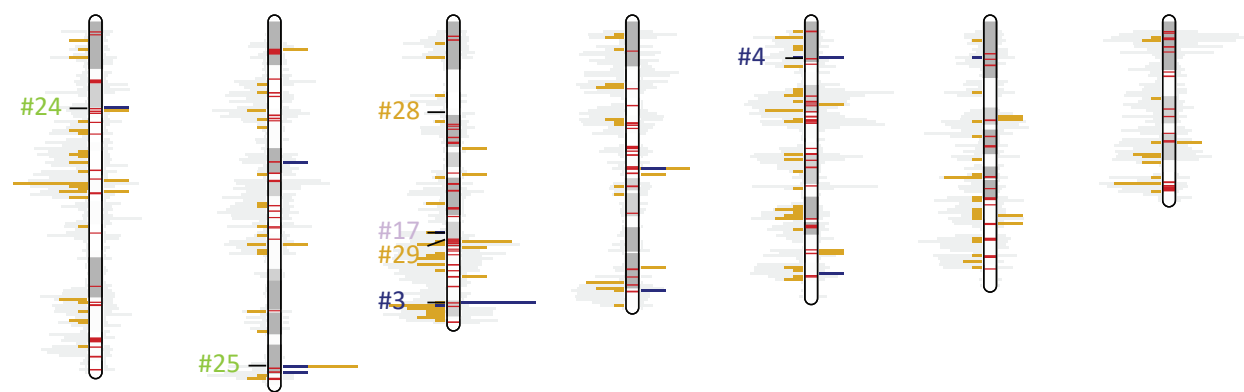

Blastocyst DMRs per $1 \mathrm{mb}$
Known GL-DMRs per $1 \mathrm{mb}$

DA methylation

Gene expression

BiX and BsX per $1 \mathrm{mb}$

50 Density of tested genes 
Fig. 1 | Parent-of-origin-specific gene expression in blastocysts

a, Schematic overview of experimental approach for the identification of parent-of-originspecific gene expression.

b, Heatmap showing row-normalized expression values of all 105 blastocyst imprint expressed (BiX) genes. Colour scale indicates $Z$ scores based on reads per million. Maternal 415 and paternal reads for the same sample are shown in separate columns.

c, Distribution of SNP-containing RNA-seq reads between maternal and paternal alleles in different gene groups (confirmed published imprinted genes, unconfirmed published imprinted genes, novel imprinting candidate genes, $\mathrm{nBiX})$.

d, RT-PCR and Sanger sequencing-based validation of allele-specific expression of confirmed published imprinted genes SIc38a4 and Otx2 on embryonic day 3.5 (E3.5).

e, RT-PCR and Sanger sequencing-based validation of allele-specific expression of nBiXs at E3.5.

f, Sequencing electropherogram showing RT-PCR and Sanger sequencing-based validation of allele-specific expression of confirmed published imprinted genes S/c38a4 and Otx2 at E6.5.

$425 \mathrm{~g}, \mathrm{RT}-\mathrm{PCR}$ and Sanger sequencing-based validation of allele-specific expression of nBiXs at E6.5.

h, Gene set enrichment analysis using Enrichr ${ }^{49}$ of mammalian phenotypes associated with loss of confirmed, novel (nBiX), or unconfirmed parent-of-origin-specifically expressed genes (left). Enrichment analysis for the same gene sets compared to genes deregulated (either increased [up] or decreased [down] expression) in gene knockout and depletion experiments (right). The eight top terms based on $p$-value are shown for each category and odds ratios are plotted. ${ }^{*}$, adj . $\mathrm{p}<0.05 ; * *$, adj. $\mathrm{p}<0.01 ; * * *$ adj. $\mathrm{p}<0.001$. 


\section{Extended Data Fig. 1 | Parent-of-origin-specific gene expression analysis in blastocysts (related to Fig. 1)}

435 a, Distribution of SNP-containing RNA-seq reads between maternal and paternal alleles in nBsX genes.

b, RT-PCR and Sanger sequencing-based analysis of allele-specific expression of Pon2 and Commd1 using E3.5 embryo samples; published imprinted genes for which we could not confirm parent-of-origin-specific expression in blastocysts.

440 c, RT-PCR and Sanger sequencing-based validation of allele-specific expression of the confirmed published imprinted genes Peg3 and Bbx at E3.5

d, RT-PCR and Sanger-sequencing-based validation of nBsX genes in E3.5 embryos.

e, RT-PCR and Sanger sequencing-based validation of allele-specific expression of the confirmed published imprinted genes Peg3 and Bbx at E6.5

445 f, RT-PCR and Sanger-sequencing-based validation of nBsX genes in E6.5 embryos.

g, Heatmap visualizing single cell sequencing data from Borensztein et al., 2017 showing parent-of-origin specific expression at stages during preimplantation development.

h, Violin plot showing absolute log2fold changes of indicated groups between ESCs (2i) and cells at an early stage of differentiation (24h after $2 \mathrm{i}$ withdrawal) ${ }^{24}$. 
Fig. 2 | DNA methylation analysis confirms genomic imprints at known GL-DMRs

a, Schematic overview of samples used for DNA methylation analysis.

b, Overview of the number of distinct $\mathrm{CpGs}$ detected and global DNA methylation levels in all samples.

c, Heatmap showing DNA methylation levels (ratio of methylated out of all reads) in 24 455 known germline DMRs (GL-DMRs) in blastocyst samples (left) and ESCs (right). 


\section{Extended Data Fig. 2 | DNA methylation analysis confirms genomic imprints at known GL- DMRs (related to Fig. 2)}

a, Immunofluorescence analysis showing Oct4 and Cdx2 expression in ICSI, androgenetic (Andro1N) and parthenogenetic (Partheno1N) blastocysts.

b, Quantification of data shown in (a). Errors bars show standard deviation between samples. Sample numbers are indicated.

c, Heatmap showing DNA methylation signal over 24 known GL-DMRs in previous data ${ }^{27}$.

d, Heatmap showing DNA methylation levels over known somatic DMRs in indicated samples.

e, RT-qPCR analysis showing expression levels of pluripotency and early differentiation markers in two androgenetic, three parthenogenetic, and three biparental ESCs cultured in $2 \mathrm{i}$ (left in each pair), and $24 \mathrm{~h}$ after $2 \mathrm{i}$ withdrawal induced release into differentiation. Mean and standard deviation values for 2 independent experiments are shown.

f, RT-qPCR analysis showing expression levels of four published imprinted genes in androgenetic, parthenogenetic and biparental ESCs cultured in $2 \mathrm{i}$ and $24 \mathrm{~h}$ after $2 \mathrm{i}$ withdrawal as in(e). 


\section{Fig. 3 | Novel DMRs in uniparental embryos}

a, Heatmap showing DNA methylation signals over all 859 identified DMRs (red, maternal DNA methylation; blue, paternal DNA methylation). Known GL-DMRs are indicated rightmost.

b, Genome browser plots showing DNA methylation signals on one paternal GL-DMR (H19) and one maternal GL-DMR (Impact). Published coordinates and coordinates determined in our analysis are indicated in blue and gold, respectively.

c, Heatmap showing all 859 identified DMRs. Hierarchical clustering was performed based on DNA methylation levels in oocyte and sperm from published data ${ }^{27}$.

d, Distribution of novel DMRs and known GL-DMRs over different genomic features. Gene promoters and 1,000 random sets of regions with a similar size and distribution as DMRs are 485 shown for reference.

e, Locus overlap analysis ${ }^{33}$ of published ChIP peaks (Zfp445 and Setdb1) on known GL-DMRs and novel DMRs.

f, Motif enrichment analysis ${ }^{38,50}$ in known GL-DMRs and novel DMRs. 


\section{Extended Data Fig. 3 | Novel DMRs in uniparental embryos (related to Fig. 3)}

a, Genome browser plot showing DNA methylation signals at the Snrp/Snrf locus. Published DMR coordinates and coordinates determined in our analysis are indicated in blue and gold, respectively.

495 b, Heatmap showing clustering of all 859 DMRs in embryos (left) and ESC lines of various parental provenance. Clustering of DMRs was performed on blastocyst data only.

c, Heatmap showing all 859 identified DMRs. Clustering was performed based on DNA methylation levels in oocyte and sperm from published datasets. ESC and somatic cell DNA methylation data extend analysis from Figure 2c. 
Fig. 4 | Intersecting parent-of-origin-specific DNA methylation and H3K27me3 with parental allele-specific gene expression

a, Plot contrasting differential DNA methylation in uniparental blastocysts ( $y$-axis) and parent-of-origin-specific gene expression (x-axis). Published and novel imprinted genes (nBiX and $\mathrm{nBsX}$ ) are shown in color, other genes are indicated in grey. Each dot represents one gene associated with the closest DMR. Selected genes were labelled.

b, Pie charts showing all 10,743 robustly detected genes, published imprinted genes with expression data, published imprinted genes which were confirmed in blastocysts (intersection with BiX), published imprinted genes which are not part of the BiX, genes that are bi-allelically expressed in blastocyst, $\mathrm{nBiX}$ and $\mathrm{nBsX}$, showing their association to different genomic features (DMRs, parent-of-origin-specific H3K27me3 on TSS). Distances of these genes from their nearest DMR are color coded. Further color codes indicate the presence of allele-specific $\mathrm{H} 3 \mathrm{~K} 27 \mathrm{me} 3$ on the gene promoter (TSS $+/-5 \mathrm{~kb}$ ) or association with a DMR in the same topologically associating domain (TAD), independent of distance. 


\section{Extended Data Fig. 4 | Integrated expression and methylome analysis (related to Fig. 4)}

a-b, Charts showing association between $71 \mathrm{nBiX}$ genes or $106 \mathrm{nBsX}$ and DMRs. Paternal $\mathrm{nBiX} / \mathrm{nBsX}$ genes are shown on blue background. Increasing color intensity indicates decreasing distances of respective gene group from nearest DMRs.

c, In-silico-derived distribution of DMR-gene pairs within the same TAD for high confidence repository imprinted genes, $\mathrm{nBiX}$ genes and equivalent genes. Observed value for each gene group is indicated by a blue line. Empirical p-values are indicated.

d, Venn diagrams showing the overlaps with proximal DMR (within $250 \mathrm{~kb}$ or in the same TAD) and H3K27me3 on gene TSS for all detected published imprinted genes, published imprinted genes with allele-specific expression in blastocyst, nBiX genes and genes biallelically expressed in blastocyst. 
Fig. 5 | Functional dependence of novel candidate genes on maternal H3K27me3 or maternal DNA methylation

a-c, Differences in allele-specific expression induced by maternal knockout (mKO) of Dnmt3I (top) and Eed (bottom) ${ }^{42,43}$. Confirmed published (a), unconfirmed published (b), and novel imprinted genes (nBiX; $c$ ) are shown in separate panels. In the plots, each arrow points from 530 the allele-specific expression ratio (ratio of SNP-containing maternal and paternal reads; $\log 2$ fold change) in wild-type toward the expression ratio of the same gene in mKO morulae. d, Pie charts showing how many genes within the represented group ( $\mathrm{nBiX}, \mathrm{nBsX}$, confirmed published imprints, unconfirmed published imprints, and equivalent genes) lose parent-oforigin specific expression following maternal deletion of either Dntm3/ or Eed in morulae ("dependent" on Dnmt3l / H3K27me3; allelic bias $>|1|$ before and $<|1|$ after maternal depletion of epigenetic regulator with a $\log 2 \mathrm{fc}>|1|$ between wt and mutant. ). Colour indicates genes that were dependent (blue) or independent (grey) of Dnmt3/ and Eed. Genes that were only detected in one dataset and did not show dependence are shown in light grey.

e, Heatmap showing the allelic bias for the indicated nBiX genes in WT or mKO morulae.

f, Bar chart showing the relative percentages of genes associated with DMRs (within $250 \mathrm{~kb}$ or in the same TAD), genes with allele-specific H3K27me3 mark near the transcription start site (TSS $+/-5 \mathrm{~kb})$, genes associated to both marks and gene associated to neither of them for the indicated groups of genes (nBiX dependent on Dnmt3l and/or H3K27me3, nBiX sensitive to Dnmt3l and/or H3K27me3 and nBiX apparently unaffected by either mechanism). 


\section{Extended Data Fig.5 | Functional dependence of novel candidate genes on maternal H3K27me3 or maternal DNA methylation (related to Figure 5)}

550 a, Venn diagrams showing overlap between the indicated groups of genes ( $\mathrm{nBiX}, \mathrm{nBsX}$, confirmed published imprinted genes, unconfirmed published imprinted genes, and equivalent genes) and genes with imprinted-like expression in control morulae from Chen et al., 2019 (light blue) or from Inoue et al., 2018 (pink circle).

b, Venn diagrams showing overlap between genes with imprinted-like expression in control morulae from Chen et al., 2019 (light blue) and from Inoue et al., 2018 (pink), and genes that loose the imprinted-like status upon maternal deletion of Dnmt3/ (genes dependent on Dnmt3I, blue) or Eed (genes dependent on H3K27me3, red) for the indicated groups of genes ( $\mathrm{nBiX}, \mathrm{nBsX}$, confirmed published imprinted genes, unconfirmed published imprinted genes, and equivalent genes).

c, Venn diagrams showing overlap between genes with imprinted-like expression in control morulae from Chen et al., 2019 (light blue) and from Inoue et al., 2018 (pink circle) that showed no dependence to H3K27me3/Dnmt3l as defined for (b), and genes with reduced imprinted-like status upon maternal deletion of Dnmt3I (genes sensitive to Dnmt3I, blue circle) or Eed (genes sensitive to H3K27me3, red circle) for the indicated groups of genes ( $\mathrm{nBiX}, \mathrm{nBsX}$ and confirmed published imprinted genes). 


\section{Fig. 6 | Novel imprinting clusters and novel genes in known clusters}

a, Gene clusters (distance between features in cluster $\leq 250 \mathrm{~kb}$ ) consisting of published imprinted genes with one or more confirmed BiX per cluster (\#1-12, blue background); clusters of published imprinted genes without confirmed parent-of-origin-specific expression (\#13-22, violet background); clusters consisting of published imprinted genes with at least one novel imprinted gene (\#23-27, green background) and clusters containing only novel candidate genes (\#28-32, yellow background). Colour code: black: published imprinted genes with parent-of-origin specific expression evidence in blastocyst (published $\mathrm{BiX}$ or $\mathrm{BsX}$ ); underlined, published imprinted gene without evidence for parent-of-origin specific expression in blastocyst; bold, novel imprinting candidate ( $\mathrm{nBiX}$ or $\mathrm{nBsX}$ ); blue, gene associated with a proximal DMR (within $250 \mathrm{~kb}$ or in the same TAD); red, gene with allelespecific H3K27me3 mark on its TSS; italic, ncRNA. Distances to the nearest DMR (and identifiers) are indicated. 


\section{Fig. 7 | Genome-wide overview of BIX and DMRs}

Visualization of the chromosomal locations of imprinted genes and chromatin marks. Novel blastocyst-specific DMRs are plotted as bars to the left in gold, known GL-DMRs are shown in blue. The density of tested regions (regions with reads in $\mu$ WGBS) are plotted in grey. Parent-of-origin expression bias is shown on the right. nBiX and nBsX are plotted in gold, known imprinted genes in blue. The density of all robustly expressed genes are plotted in grey. All clusters of Figure 6 are indicated. The locations of all allele-specific H3K27me3 peaks are shown as red bands overlaid on the chromosome ideograms. 


\section{METHODS}

Animals. Animal procedures complied with the statutes of the Animals (Scientific

Procedures) Act, 1986, approved by the University of Bath Animal Welfare and Ethical

Review Body and the Biosciences Services Unit. Wild-type mouse strains were bred from stocks in-house or otherwise supplied by Charles River (L'Arbresle, France) or MRC Harwell. The strain B6D2F1 (C57BL/6xDBA2) was generally used as a source of unfertilized metaphase

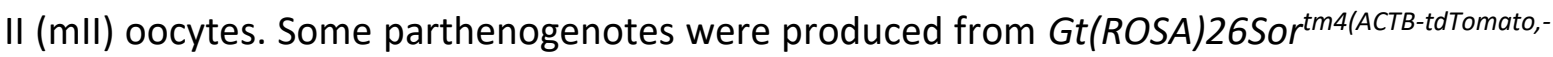
EGFP)Luo (mT) oocytes and we generated a 129/Sv-J line carrying a single, ubiquitouslyexpressed pCAG-eGFP transgene (129/Sv-J-eGFP+/-; Suzuki et al., 2014) and used sperm from hemizygotes to generate androgenetic haploid embryos for ES cell derivation. Recipient surrogate mothers were of the strain ICR (CD-1) in embryo transfer.

Oocytes. Oocyte collection was essentially performed as described previously ${ }^{51,52}$. Briefly, IU of pregnant mare serum gonadotropin (PMSG) and 5 IU human chorionic gonadotropin (hCG) 48 h apart. Oocyte-cumulus complexes were collected into M2 medium (Specialty Media, USA) and dispersed with hyaluronidase to denude mll oocytes, which were washed and cultured in kalium simplex optimized medium (KSOM; Specialty Media, USA) equilibrated in an incubator at $37^{\circ} \mathrm{C}$ containing $5 \%(\mathrm{v} / \mathrm{v})$ humidified $\mathrm{CO}_{2}$ in air until required.

Sperm. Preparation of sperm from $129 /$ Sv-J-eGFP $^{+/}$males was essentially as described previously (Suzuki et al., 2014). Epidydimides from 12-week-old males were minced with fine scissors in nuclear isolation medium (NIM; $125 \mathrm{mM} \mathrm{KCl}, 2.6 \mathrm{mM} \mathrm{NaCl}, 7.8 \mathrm{mM} \mathrm{Na}_{2} \mathrm{HPO}_{4}$, 
$1.4 \mathrm{mM} \mathrm{KH} 2 \mathrm{PO}_{4}, 3.0 \mathrm{mM}$ EDTA; $\mathrm{pH} 7.0$ ) and sperm allowed to disperse. The sperm were washed in NIM and treated in NIM containing $1.0 \%(\mathrm{w} / \mathrm{v}) 3-[(3-$ cholamidopropyl) dimethylammonio]-1-propanesulfonate (CHAPS) at room temperature. The suspension was gently pelleted and sperm resuspended in ice-cold NIM and held on ice until required. Just prior to ICSI, $50 \mu$ l of the sperm suspension was mixed with $20 \mu$ l of a solution of $12 \%(\mathrm{w} / \mathrm{v})$ polyvinylpyrrolidone (PVP, average $M_{r} \approx 360,000$; Sigma, UK).

620 Production of uniparental haploid embryos. To establish androgenic haploid ES (ahES) cell lines, sperm from 129/Sv-J-eGFP+/- hemizygous males were injected using a piezo-actuated micromanipulator (Prime Tech Ltd., Japan) into B6D2F1 mll oocytes enucleated as described previously (Wakayama et al., 1998): mll oocytes were placed in M2 medium containing 5 $\mu \mathrm{g} / \mathrm{ml}$ cytochalasin B and spindles were removed. At least $1 \mathrm{~h}$ post-enucleation, sperm heads were injected followed by culture in $\mathrm{KSOM}$ for $6 \mathrm{~h}\left(37^{\circ} \mathrm{C}\right.$, humidified $5 \% \mathrm{CO}_{2}[\mathrm{v} / \mathrm{v}]$ in air) before recording the morphology of the resultant embryos. Embryos were separated according to whether they possessed a single second polar body $\left(\mathrm{Pb}_{2}\right)$ and pronucleus $(\mathrm{pn})$ and culture was continued for 3-4 days to be utilised for ahES cell derivation. Parthenogenetic embryos were derived by strontium chloride triggered oocyte activation in calcium free medium followed by in vitro culture to the blastocyst stage in KSOM.

Parthenogenesis. Activation of membrane Tomato homozygous $\left(m T^{+/+}\right)$transgenic or $129 /$ SvJ oocytes to produce parthenogenetic haploid embryos was by exposure to medium containing $10 \mathrm{mM} \mathrm{SrCl}_{2}, 16-17.5$ h post-hCG, essentially as described ${ }^{53}$. 
Sperm microinjection (ICSI). When required, $50 \mu$ of sperm suspension was mixed with 20

$\mu$ of polyvinylpyrrolidone (PVP, average $M_{r} \approx 360,000$; Sigma-Aldrich) solution (15\% [w/v]) and sperm injected (ICSI) into oocytes in a droplet of M2 medium, within 60 min, essentially as described ${ }^{51}$. Injected oocytes were transferred to KSOM under mineral oil equilibrated in humidified $5 \% \mathrm{CO}_{2}\left(\mathrm{v} / \mathrm{v}\right.$ air) at $37^{\circ} \mathrm{C}$ for embryo culture.

Establishment and culture of androgenetic and parthenogenetic haploid ES cells. Haploid

640 ES cells were established and cultured in 2i/LIF medium as previously described ${ }^{13,14}$. Androgenetic haploid ES cells be maintained only in the presence of LIF and not in $2 \mathrm{i}$ alone. Both androgenetic and parthenogenetic haploid ES cells were recurrently sorted based on

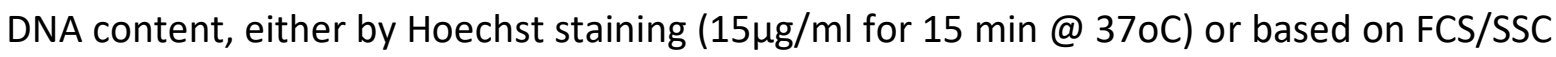
parameters ${ }^{54}$. The following ESC lines were used in this study: ES-f1 at $p 20$ (Rex1::GFPd2 reporter cell line (Leeb 2014), ES-f2 at p17 (129/B6 F1 hybrid female line), ES-m1 at p16 (E14TG2a male ESC line, ES-m2 p8 (male 129 derived ESC line), ES-m3 p8 (male ES cell line of mixed background carrying a floxed but intact Mek1 allele), pES1 p12 (haploid parthenogenetic Rex1::GFP reporter cell line, 129 background 55, pES2 p8 (haploid parthenogenetic ESC line P1 from a 129 background), pES3 p8 (haploid parthenogenetic ESC line T8, carrying a constitutive dtTomato reporter from a 129 background), pES4 p12 (haploid parthenogenetic ESC line H129-1 from a 129 background ${ }^{14}$ ), aES1 p12 (haploid androgenetic ESC line A6GFP from a 129 background, carrying a constitutively active GFP transgene), aES2 p8 (haploid androgenetic ESC line A7 from a 129 background), aES3 p8 (haploid androgenetic ESC line A11 from a 129 background). 
Androgenetic haploid ES cell nucleus injection. Suspensions ahES were mixed with $20 \mu \mathrm{l}$ of a solution of $12 \%(\mathrm{w} / \mathrm{v})$ PVP and injected into mll oocytes essentially as described previously (Wakayama et al., 1998). Following a recovery period of 10-15 min, injected oocytes were activated by incubation at $37^{\circ} \mathrm{C}$ under $5 \%(\mathrm{v} / \mathrm{v})$ humidified $\mathrm{CO}_{2}$ in air for $2-4 \mathrm{~h}$ in calcium-free CZB-G medium supplemented with $10 \mathrm{mM} \mathrm{SrCl}_{2}$ (REF). After $6 \sim 8 \mathrm{~h}$, the number of $\mathrm{Pb}_{2}$ and $\mathrm{pn}$ in embryos was determined and those with a single $\mathrm{Pb}_{2}$ and two pn ( $\left.\mathrm{Pb}_{2}-\mathrm{pn} 2\right)$ placed in a separate drop and culture continued in KSOM. Where appropriate, embryos at the 2-cell stage were transferred to pseudopregnant CD-1 (ICR) females by as described ${ }^{52}$. As a proofof-principle, we generated a single offspring by cumulus cell nuclear transfer essentially as described previously ${ }^{56}$.

Preparation of ahES cells for nt. Following culture of FACS-purified ahES cells at $37^{\circ} \mathrm{C}$ in humidified $5 \%(\mathrm{v} / \mathrm{v}) \mathrm{CO}_{2}$ in air, cell suspensions were prepared as previously described ${ }^{13,54}$. Briefly, cells were washed with DMEM medium followed by calcium-free PBS and incubated with trypsin/EDTA for $3 \mathrm{~min}$ at $37^{\circ} \mathrm{C}$. Trypsinization was quenched by the addition of $5 \mathrm{ml}$ ES/DMEM (DMEM supplemented with 5\% [v/v] FCS/LIF; Leeb and Wutz, 2011) and cells dissociated by gentle pipetting. Single cell suspensions were pelleted by centrifugation (1,100rpm, $5 \mathrm{~min})$ and resuspended in fresh ES/DMEM medium. Single cell ahES cell suspensions were placed on ice and used immediately for micromanipulation. In some cases, haploid cells were enriched by FACS sorting immediately prior to micromanipulation. Cell aggregates were removed by passing suspensions though a $50 \mu \mathrm{m}$ cell strainer (FALCON) into a polypropylene FACS tube (BD). To avoid Hoechst toxicity, we employed SSC and FSC as FACS Aria parameters for haploid and diploid population separation. Enriched haploid ES 
cells were collected into an ice-cold FACS tube containing $1 \mathrm{ml} \mathrm{ES/DMEM} \mathrm{supplemented} \mathrm{with}$ serum and immediately used for micromanipulation. G1 cell selection was further attempted by selecting smaller cells as nucleus donors.

Differentiation assay. To evaluate differentiation potential of parthenogenetic and androgenetic cells, the expression level of naïve pluripotency and early differentiation markers was analysed in comparison to biparental control by RT-qPCR. ES-m1, ES-m2, ES-f1, pES1, pES3 pES4, aES1 and aES2 cell lines were plated in N2B27 based 2i/LIF medium at a final density of $10^{4}$ cells $/ \mathrm{cm}^{2}$. On the next day, cells were washed with PBS and medium was exchanged to either N2B27 without $2 \mathrm{i} /$ LIF to induce differentiation, or fresh N2B27 + 2i/LIF for the undifferentiated controls. After $24 \mathrm{~h}$, cells were washed twice with PBS and harvested in RNA Lysis buffer $+1 \%$ 2-merchaptothanol and stored at $-80^{\circ} \mathrm{C}$ before isolation of RNA using the EXTRACTME Total RNA Kit (Blirt). RNA was reverse-transcribed into cDNA using the SensiFAST cDNA Synthesis Kit (Bioline). Pluripotency and early differentiation marker as well as selected known imprinted genes expression was determined by qPCR using the Sensifast SYBR No Rox-Kit (Bioline).

Statistical analysis. Statistical differences between pairs of data sets were analysed by a Chisquared test.

Imprinted gene assignment from RNA-seq data. Single blastocysts from reciprocal crosses (natural mating) between Mus musculus musculus C57BL/6 (B6) and Mus musculus castaneus (cast) were lysed and RNA extracted. Samples were processed using a SMARTSeq 2 compatible protocol and processed as described ${ }^{25}$. For imprinted gene assignment, we 
bioRxiv preprint doi: https://doi.org/10.1101/2020.11.03.366948; this version posted November 5, 2020. The copyright holder for this preprint (which was not certified by peer review) is the author/funder, who has granted bioRxiv a license to display the preprint in perpetuity. It is made available under aCC-BY-NC-ND 4.0 International license.

tested whether the difference between paternal and maternal reads per gene was significant using DESeq2. Only reads covering annotated SNPs for B6 and cast were used for the analysis. The number of reads per gene that could be assigned to one of the strains by the SNP information was taken from an intermediate result of the Allelome.Pro pipeline 8,57 and used to create a count table for all samples from forward (B6 x Cast) and reverse crosses (Cast x B6). Samples 4 (less than $5 \%$ of reads mapping to the reference genome) and 6 (too low number of total reads) were removed from the analysis pipeline. Moreover, genes on the X-chromosome and genes with fewer than ten SNP spanning reads in at least one sample were removed from further analysis. We then employed DESeq2 to test for significant differences in maternal and paternal expression, in addition to delineating strain-specific expression using an adjusted $p$-value $\leq 0.05$ as cut-off; genes that passed this threshold but were not consistently strain biased across all samples were not considered to be strain specific. This is the case e.g. for significantly regulated genes that are, however, detected only in one direction of crosses. The list of 'published imprinted genes' was comprises genes previously reported to be imprinted in the literature ${ }^{1,8}$ and genes present in 4 different imprinting repositories (Mousebook, Otago, Geneimprint, Wamidex). From 388 unique imprinted gene names, 238 were also found in our dataset and could be assigned mgi gene symbols. Of these genes, 10 were located on the $X$ chromosome and 51 were not represented by at least 10 SNP-overlapping reads; these genes were excluded from further analysis while 178 genes remained in the analysis pipeline. An additional 3 gene names were associated with predicted genes and hence removed from further analysis. To further exclude the possibility of erroneously calling imprinted genes due to reads assigned to overlapping transcripts, we only included genes if reads could be unambiguously assigned 
bioRxiv preprint doi: https://doi.org/10.1101/202011.03 366948; this version posted November 5,2020 . The copyright holder for this preprint (which was not certified by peer review) is the author/funder, who has granted bioRxiv a license to display the preprint in perpetuity. It is made available under aCC-BY-NC-ND 4.0 International license.

to a specific transcript. We further excluded genes that were not robustly expressed (genes with less than 12 reads in at least 4 samples). Genes with a $L 2 F C>|0.5|$ between maternal and paternal alleles that fulfilled previous criteria and were consistently parentally biased across all samples were defined as 'blastocyst-skewed expressed' genes (BsX genes). Additionally, genes that showed a $70: 30$ expression ratio in at least $60 \%$ of samples in each cross between the parental alleles were considered as BiX genes ('blastocyst-imprinted expressed' genes).

Evaluation of imprinted gene sets. We examined the identified and previously published imprinted genes using three bioinformatics approaches: First, gene set enrichment analysis was performed using Enrichr ${ }^{49}$ against a database of genes whose disruption is associated with known phenotypic changes (MGI_Mammalian_Phenotype_2017) and against a database of genes deregulated in loss-of-function experiments (TF-LOF Expression_from_GEO). The top 8 terms sorted by p-value were selected. Second, we obtained allele-specific single-cell gene expression data from oocytes and preimplantation embryos ${ }^{18}$ from GEO (GSE80810) and used these data to confirm parentally-biased allelespecific expression of published, $\mathrm{nBiX}, \mathrm{nBsX}$, but not of unconfirmed published imprinted genes throughout preimplantation development. Third, comparison of absolute log2FCs between ESCs cultured in $2 \mathrm{i}$ and $24 \mathrm{~h}$ after induction of differentiation by $2 \mathrm{i}$ withdrawal ${ }^{24}$ for the different groups of genes. Genes showing parentally-biased allele-specific expression, genes showing equal expression from both alleles, known imprinted genes and all genes were used as gene groups to compare the dynamics in gene expression. 
Whole genome bisulfite sequencing. Sequencing libraries for DNA methylation mapping were prepared using the $\mu$ WGBS protocol ${ }^{25}$. Starting directly from lysed cells in digestion buffer, proteinase $\mathrm{K}$ digestion was performed at $50^{\circ} \mathrm{C}$ for 20 minutes. Custom-designed methylated and unmethylated oligonucleotides were added at a concentration of $0.1 \%$ to serve as spike-in controls for monitoring bisulfite conversion efficiency. Bisulfite conversion was performed using the EZ DNA Methylation-Direct Kit (Zymo Research, D5020) according to the manufacturer's protocol, with the modification of eluting the DNA in only $9 \mu \mathrm{l}$ of elution buffer. Bisulfite-converted DNA was used for single-stranded library preparation using the EpiGnome Methyl-Seq kit (Epicentre, EGMK81312) with the described modifications. Quality control of the final library was performed by measuring DNA concentrations using the Qubit dsDNA HS assay (Life Technologies, Q32851) on Qubit 2.0 Fluorometer (Life Technologies, Q32866) and by determining library fragment sizes with the Agilent High Sensitivity DNA Analysis kit (Agilent, 5067-4626) on Agilent 2100 Bioanalyzer Station (Agilent, G2939AA). All libraries were sequenced by the Biomedical Sequencing Facility at CeMM using the 2x75bp paired-end setup on the Illumina HiSeq 3000/4000 platform.

DNA methylation data processing. Sequencing adapter fragments were trimmed using Trimmomatic v0.32 ${ }^{58}$. The trimmed reads were aligned with Bismark v0.12.2 ${ }^{59}$ with the following parameters: --minins 0 --maxins 6000 --bowtie2, which uses Bowtie2 v2.2.4 ${ }^{60}$ for read alignment to the mm10 assembly of the mouse reference genome. Duplicate reads were removed as potential PCR artefacts and reads with a bisulfite conversion rate below 90\% or with fewer than three cytosines outside a CpG context (required to confidently assess 
bisulfite conversion rate) were removed as potential post-bisulfite contamination. DNA methylation levels estimated by the Bismark extractor were loaded into $\mathrm{R}$ retaining all CpGs that were covered with at least three reads in at least two samples. We then used $d m r s e q^{31}$ to identify consistently methylated regions of neighboring CpGs ( $n=168,061$ regions) between androgenote, parthenogenote, and ICSI blastocysts (two replicates per sample group, total $n=6)$. We retained all regions with opposing DNA methylation levels in uniparental vs. ICSI blastocysts (i.e., either $a h>I C S C I>p h$, or $a h<I C S I<p h$ ), with at least 100 reads total coverage (across all replicates), and with a minimum length of $100 \mathrm{bp}$. Testing those regions $(n=77,358)$ for significant differences in DNA methylation levels by sample group (FDR-adjusted $\mathrm{p}$-value $<=0.1, \mid$ ah-ph $\mid>=30$ percentage points, $\left|\beta_{\text {ah }}\right|>=0.25,\left|\beta_{\text {ph }}\right|$ $>=0.25$ ) yielded 859 candidate DMRs. To enable comparison of these DMRs with the DNA methylation status in oocytes, sperm, and the ICM, we obtained published MethylC-Seq data (Wang et al., 2014) from GEO (GSE56697).

Positional, region overlap, and motif enrichment analysis. We examined the identified genomic DMR regions with two complementary approaches: First, we used Locus Overlap Analysis ${ }^{33}$ (LOLA; v1.12.0) to identify significant overlaps with experimentally determined transcription factor binding sites from publicly available ChIP-seq data. To this end, we used 791 ChIP-seq peak datasets from the LOLA Core database and we additionally added Znf445 binding peaks ${ }^{37}$. We considered only terms with an 8-fold enrichment and an FDR-adjusted p-value below 0.005 significant. We focused on datasets from embryonic stem cells that were at least 1.5 -fold more enriched in DMRs than in promoter regions. Second, we searched the DNA sequences underlying each DMR for matches to known DNA binding 
motifs from the HOCOMOCO database v11 ${ }^{38}$. For this search, we used FIMO ${ }^{50}$ (v4.10.2) (parameters: --no-qvalue --text --bgfile motif-file), and regions with at least one hit $(\mathrm{p}<$ 0.0001) were counted. To test for motif enrichment, we used Fisher's exact test. Motifs with a 4-fold enrichment and an FDR-adjusted p-value below 0.005 were considered significant. We focused on motifs at least 1.5-fold more enriched in DMRs than in promoter regions.

Analysis of allele-specific H3K27me3. We defined parent-of-origin-specific H3K27me3 imprints using published allele-specific ChIP-seq data from the ICM ${ }^{41}$. To this end, we downloaded peak coordinates from GEO (GSE76687), converted the coordinates to the mm10 genome assembly using liftOver, and associated peaks with a gene if a peak was found within $5 \mathrm{~kb}$ of its transcription start site.

Analysis of DNA-methylation-dependent and H3K27me3-dependent allelic expression. To assess dependence of the allelic expression bias of imprinted genes on DNA methylation and H3K27me3, we obtained allele-specific RNA-seq data before and after maternal knockout (mKO) of Dnmt3l and Eed ${ }^{42,43}$ from GEO (GSE130115 and GSE116713). First, genes were defined as imprinted in morulae if they showed a $\log 2 \mathrm{FC}$ between maternal and paternal alleles $>|1|$ in control morulae in at least one of the two datasets. Genes that lose their imprinted-like status ( $\log 2 \mathrm{FC}$ control/ $\log 2 \mathrm{FC}$ KO $>1 \& \log 2 \mathrm{FC}$ KO between -1 and 1$)$ upon maternal deletion of Dnmt3l or Eed were considered to be dependent on maternally deposited DNA methylation or H3K27me3, respectively. 
cDNA was used as a template to amplify PCR fragments covering at least one SNP per gene.

Resulting fragments were then analysed by Sanger Sequencing.

Topologically associating domains (TAD). Because TAD positions are known to be relatively invariant across different tissues, we employed TADs coordinates defined in mouse ES cells 61 as a proxy for E4.5 blastocysts. DMR and imprinted genes are defined to be within the same TAD if the centre of DMR and gene transcription start sites are located within the same TADs (DMRs falling into TAD boarders up to $50 \mathrm{~kb}$ are excluded from downstream analysis). The control set was generated by randomly shifting genome coordinates of both genes and DMR on each chromosome 1000 times, so that pair-wise distances between genes and DMR are kept the same. The number of imprinted genes having a DMR associated within the same TAD was calculated for both the control and the experiment datasets. 


\section{REFERENCES}

820 1. Tucci, V., Isles, A.R., Kelsey, G., Ferguson-Smith, A.C. \& Erice Imprinting, G. Genomic Imprinting and Physiological Processes in Mammals. Cell 176, 952-965 (2019).

2. Sanli, I. \& Feil, R. Chromatin mechanisms in the developmental control of imprinted gene expression. The International Journal of Biochemistry \& Cell Biology 67, 139-147 (2015).

825 3. Surani, M.A., Barton, S.C. \& Norris, M.L. Development of reconstituted mouse eggs suggests imprinting of the genome during gametogenesis. Nature 308, 548-50 (1984).

4. McGrath, J. \& Solter, D. Completion of mouse embryogenesis requires both the maternal and paternal genomes. Cell 37, 179-83 (1984).

$8305 . \quad$ Morison, I.M., Ramsay, J.P. \& Spencer, H.G. A census of mammalian imprinting. Trends Genet 21, 457-65 (2005).

6. Schulz, R. et al. WAMIDEX: a web atlas of murine genomic imprinting and differential expression. Epigenetics 3, 89-96 (2008).

7. Blake, A. et al. MouseBook: an integrated portal of mouse resources. Nucleic Acids Res 38, D593-9 (2010).

8. Andergassen, D. et al. Mapping the mouse Allelome reveals tissue-specific regulation of allelic expression. Elife 6(2017).

9. Inoue, A., Jiang, L., Lu, F., Suzuki, T. \& Zhang, Y. Maternal H3K27me3 controls DNA methylation-independent imprinting. Nature 547, 419 (2017).

840 10. Bourc'his, D., Xu, G.L., Lin, C.S., Bollman, B. \& Bestor, T.H. Dnmt3L and the establishment of maternal genomic imprints. Science 294, 2536-9 (2001).

11. Schulz, R. et al. The parental non-equivalence of imprinting control regions during mammalian development and evolution. PLoS Genet 6, e1001214 (2010). 
12. Ferguson-Smith, A.C. \& Bourc'his, D. The discovery and importance of genomic imprinting. Elife 7(2018).

13. Leeb, M. \& Wutz, A. Derivation of haploid embryonic stem cells from mouse embryos. Nature 479, 131-4 (2011).

14. Leeb, M. et al. Germline potential of parthenogenetic haploid mouse embryonic stem cells. Development 139, 3301-5 (2012).

15. Yang, H. et al. Generation of genetically modified mice by oocyte injection of androgenetic haploid embryonic stem cells. Cell 149, 605-17 (2012).

16. Wan, H. et al. Parthenogenetic haploid embryonic stem cells produce fertile mice. Cell Research 23, 1330-1333 (2013).

17. Li, Z.-K. et al. Generation of Bimaternal and Bipaternal Mice from Hypomethylated Haploid ESCs with Imprinting Region Deletions. Cell Stem Cell 23, 665-676.e4 (2018).

18. Borensztein, $M$. et al. Xist-dependent imprinted $X$ inactivation and the early developmental consequences of its failure. Nat Struct Mol Biol 24, 226-233 (2017).

19. Monk, D., Mackay, D.J.G., Eggermann, T., Maher, E.R. \& Riccio, A. Genomic imprinting disorders: lessons on how genome, epigenome and environment interact. Nature Reviews Genetics 20, 235-248 (2019).

20. Duffié, R. et al. The Gpr1/Zdbf2 locus provides new paradigms for transient and dynamic genomic imprinting in mammals. Genes \& Development 28, 463-478 (2014).

21. Czermin, B. et al. <em >Drosophila</em $>$ Enhancer of Zeste/ESC Complexes Have a Histone H3 Methyltransferase Activity that Marks Chromosomal Polycomb Sites. Cell 111, 185-196 (2002).

22. Terranova, R. et al. Polycomb Group Proteins Ezh2 and Rnf2 Direct Genomic Contraction and Imprinted Repression in Early Mouse Embryos. Developmental Cell $15,668-679$ (2008). 
23. Pereira, C.F. et al. ESCs require PRC2 to direct the successful reprogramming of differentiated cells toward pluripotency. Cell Stem Cell 6, 547-56 (2010).

24. Lackner, A. et al. Cooperative molecular networks drive a mammalian cell state transition. bioRxiv, 2020.03.23.000109 (2020).

25. Farlik, M. et al. Single-cell DNA methylome sequencing and bioinformatic inference of epigenomic cell-state dynamics. Cell Rep 10, 1386-97 (2015).

26. Li, W. et al. Androgenetic haploid embryonic stem cells produce live transgenic mice. Nature 490, 407-11 (2012).

27. Wang, L. et al. Programming and Inheritance of Parental DNA Methylomes in Mammals. Cell 157, 979-991 (2014).

28. Gigante, S. et al. Using long-read sequencing to detect imprinted DNA methylation. Nucleic Acids Research 47, e46-e46 (2019).

29. Matsuzaki, H., Okamura, E., Shimotsuma, M., Fukamizu, A. \& Tanimoto, K. A Randomly Integrated Transgenic <em $>\mathrm{H} 19</$ em $>$ Imprinting Control Region Acquires Methylation Imprinting Independently of Its Establishment in Germ Cells. Molecular and Cellular Biology 29, 4595-4603 (2009).

30. Li, X. et al. A Maternal-Zygotic Effect Gene, <em $>$ Zfp57</em>, Maintains Both Maternal and Paternal Imprints. Developmental Cell 15, 547-557 (2008).

31. Korthauer, K., Chakraborty, S., Benjamini, Y. \& Irizarry, R.A. Detection and accurate false discovery rate control of differentially methylated regions from whole genome bisulfite sequencing. Biostatistics 20, 367-383 (2018).

890 32. Braidotti, G. et al. The Air noncoding RNA: an imprinted cis-silencing transcript. Cold Spring Harb Symp Quant Biol 69, 55-66 (2004).

33. Sheffield, N.C. \& Bock, C. LOLA: enrichment analysis for genomic region sets and regulatory elements in R and Bioconductor. Bioinformatics 32, 587-589 (2015). 
34. Sánchez-Castillo, $M$. et al. CODEX: a next-generation sequencing experiment database for the haematopoietic and embryonic stem cell communities. Nucleic Acids Research 43, D1117-D1123 (2014).

35. Dunham, I. et al. An integrated encyclopedia of DNA elements in the human genome. Nature 489, 57 (2012).

36. Leung, D. et al. Regulation of DNA methylation turnover at LTR retrotransposons and imprinted loci by the histone methyltransferase Setdb1. Proceedings of the National Academy of Sciences 111, 6690-6695 (2014).

37. Takahashi, N. et al. ZNF445 is a primary regulator of genomic imprinting. Genes Dev 33, 49-54 (2019).

38. Kulakovskiy, I.V. et al. HOCOMOCO: towards a complete collection of transcription 905 factor binding models for human and mouse via large-scale ChIP-Seq analysis. Nucleic Acids Research 46, D252-D259 (2017).

39. Rodriguez-Jato, S., Nicholls, R.D., Driscoll, D.J. \& Yang, T.P. Characterization of cisand trans-acting elements in the imprinted human SNURF-SNRPN locus. Nucleic Acids Res 33, 4740-53 (2005).

40. Dixon, J.R. et al. Topological domains in mammalian genomes identified by analysis of chromatin interactions. Nature 485, 376-380 (2012).

41. Zheng, $H$. et al. Resetting Epigenetic Memory by Reprogramming of Histone Modifications in Mammals. Molecular Cell 63, 1066-1079 (2016).

42. Chen, Z., Yin, Q., Inoue, A., Zhang, C. \& Zhang, Y. Allelic H3K27me3 to allelic DNA methylation switch maintains noncanonical imprinting in extraembryonic cells. Science Advances 5, eaay7246 (2019).

43. Inoue, A., Chen, Z., Yin, Q. \& Zhang, Y. Maternal Eed knockout causes loss of H3K27me3 imprinting and random X inactivation in the extraembryonic cells. Genes Dev 32, 1525-1536 (2018). 
44. Ferguson-Smith, A.C. Genomic imprinting: the emergence of an epigenetic paradigm. Nature Reviews Genetics 12, 565-575 (2011).

45. Verona, R.I., Mann, M.R. \& Bartolomei, M.S. Genomic imprinting: intricacies of epigenetic regulation in clusters. Annu Rev Cell Dev Biol 19, 237-59 (2003).

46. Barlow, D.P. \& Bartolomei, M.S. Genomic Imprinting in Mammals. Cold Spring Harbor Perspectives in Biology 6(2014).

47. Choi, J. et al. Prolonged Mek1/2 suppression impairs the developmental potential of embryonic stem cells. Nature 548, 219-223 (2017).

48. Sagi, I. et al. Distinct Imprinting Signatures and Biased Differentiation of Human Androgenetic and Parthenogenetic Embryonic Stem Cells. Cell Stem Cell 25, 419-432 e9 (2019).

49. Chen, E.Y. et al. Enrichr: interactive and collaborative HTML5 gene list enrichment analysis tool. BMC Bioinformatics 14, 128 (2013).

50. Grant, C.E., Bailey, T.L. \& Noble, W.S. FIMO: scanning for occurrences of a given motif. Bioinformatics 27, 1017-1018 (2011).

51. Yoshida, N. \& Perry, A.C. Piezo-actuated mouse intracytoplasmic sperm injection (ICSI). Nat Protoc 2, 296-304 (2007).

52. Suzuki, T., Asami, M. \& Perry, A.C. Asymmetric parental genome engineering by Cas9 during mouse meiotic exit. Sci Rep 4, 7621 (2014).

53. Suzuki, T. et al. Mice produced by mitotic reprogramming of sperm injected into haploid parthenogenotes. Nature Communications 7, 12676 (2016).

54. Leeb, M., Perry, A.C.F. \& Wutz, A. Establishment and Use of Mouse Haploid ES Cells. Curr Protoc Mouse Biol 5, 155-185 (2015). 
55. Leeb, M., Dietmann, S., Paramor, M., Niwa, H. \& Smith, A. Genetic exploration of the exit from self-renewal using haploid embryonic stem cells. Cell Stem Cell 14, 385-93 (2014).

56. Wakayama, T., Perry, A.C.F., Zuccotti, M., Johnson, K.R. \& Yanagimachi, R. Full-term development of mice from enucleated oocytes injected with cumulus cell nuclei. Nature 394, 369-374 (1998).

57. Andergassen, D. et al. Allelome.PRO, a pipeline to define allele-specific genomic features from high-throughput sequencing data. Nucleic Acids Res 43, e146 (2015).

58. Bolger, A.M., Lohse, M. \& Usadel, B. Trimmomatic: a flexible trimmer for Illumina sequence data. Bioinformatics 30, 2114-2120 (2014).

59. Krueger, F. \& Andrews, S.R. Bismark: a flexible aligner and methylation caller for Bisulfite-Seq applications. Bioinformatics 27, 1571-1572 (2011).

60. Langmead, B. \& Salzberg, S.L. Fast gapped-read alignment with Bowtie 2. Nature Methods 9, 357-359 (2012).

61. Stevens, T.J. et al. 3D structures of individual mammalian genomes studied by singlecell Hi-C. Nature 544, 59-64 (2017). 